February 2023

Gender wage and longevity gaps and the design of retirement systems

Francesca Barigozzi, Helmuth Cremer and Jean-Marie Lozachmeur 


\title{
Gender wage and longevity gaps and the design of retirement systems ${ }^{1}$
}

\author{
Francesca Barigozzi $^{2} \quad$ Helmuth Cremer $^{3} \quad$ Jean-Marie Lozachmeur ${ }^{4}$
}

January 2021, revised February 2023

\footnotetext{
${ }^{1}$ We thank the Associate Editor and the reviewers for their detailed and constructive commnets. This paper has been presented at the University of Tulane, University of Bologna, at the 2021 IEB Workshop on Public Policies: Gender and Health and at the 20th Louis-André Gérard-Varet conference. We thank seminar participants for their constructive comments and especially Matthew Wakefield for his suggestions. Financial support from the Chaire "Marché des risques et creation de valeur" of the FdR/SCOR is gratefully acknowledged. Helmuth Cremer and Jean-Marie Lozachmeur gratefully acknowledge the funding received by TSE from ANR under grant ANR-17-EURE-0010 (Investissements d'Avenir program). Declarations of interest: none.

${ }^{2}$ University of Bologna, Italy, Email: francesca.barigozzi@unibo.it.

${ }^{3}$ Toulouse School of Economics, France, Email: helmuth.cremer@tse-fr.eu.

${ }^{4}$ Toulouse School of Economics, France, Email: Jean-Marie.Lozachmeur@tse-fr.eu.
} 


\begin{abstract}
We study the design of pension benefits for male and female workers. Women live longer than men but have a lower wage. Individuals can be single or live in couples who pool their incomes. Social welfare is utilitarian but an increasing concave transformation of individuals' lifetime utilities introduces the concern for redistribution across individuals with different lifespans.

We derive the optimal direction of redistribution and show how it is affected by a gender neutrality rule. With singles only, a simple utilitarian solution implies redistribution from males to females. When the transformation is sufficiently concave redistribution may or may not be reversed. With couples only, the ranking of gender retirement ages is always reversed when the transformation is sufficiently concave.

Under gender neutrality pension schemes must be self-selecting. Gender neutrality implies distortions of retirement decisions, limits redistribution and, negatively affects the group towards which redistribution is targeted. With couples, a first best that implies a lower retirement age for females can be implemented by a gender-neutral system. Otherwise, gender neutrality implies equal retirement ages and restricts the possibility to compensate the shorter-lived individuals. Calibrated simulations show that when singles and couples coexist, gender neutrality substantially limits redistribution in favor of single women and fully prevents redistribution in favor of male spouses.
\end{abstract}

Keywords: gender wage gap, gender gap in longevity, retirement systems. JEL classification: H55, H31, H21. 


\section{Introduction}

The longevity gap and the wage gap are two important factors in gender inequality, particularly when it comes to the retirement period. On average, women outlive men but, having earned less during their active life, they tend to have less savings when retiring. As a result, women are at greater risk of poverty in later life than men (Policy Department, European Parliament, 2019).

The longevity gap has been decreasing during the last decades, but it continues to be significant. Among OECD nations, the difference in life expectancy at birth is currently around four to six year (seven in Japan); see Goldin and Lleras-Muney (2019). ${ }^{1}$

Turning to the gender wage gap, the persisting and systematic gender differences in employment outcomes have been extensively studied; see Bertrand (2020) for a recent survey. The gap in earnings is synthesized by the gender wage gap: on average, women in the EU earn around $15 \%$ less per hour than men (Eurostat 2020); see also Blau and Kahn (2018). Later in life, the gender wage gap translates in a (largely amplified) gender pension gap, whose importance has been recently acknowledged by governments and international organizations. ${ }^{2}$

In the EU, pension systems manage to reduce the inequalities induced by the earning gap to some extent. Still, different earning histories and child care involvement continue to be reflected in a significant gender pension gap; see OECD (2021). In 2019, the average female pension income was $37 \%$ lower than that of men (European Parliament resolution of Jan.30, 2020). The importance of solidarity and redistribution has been recently confirmed by the Resolution of 14 June 2017 on the need for an EU strategy to end and prevent the gender pension gap. As a result, in many Member States, women are still granted pension rights for child care (premium for child care and gender-specific retirement ages) subject to certain conditions.

\footnotetext{
${ }^{1}$ The explanation of these gender differences in mortality is subject to some debate, and there are several schools of thought, see Cullen et al. (2016) and references within. Theories range from those stipulating a selective female survival advantage on a "hard-wired" biologic basis to more sociological and behavioral based explanations.

${ }^{2}$ See OECD (2021) and, among others, the documents from UK Parliament (2022) with title "The Gender Pension Gap," and the one from World Economic Forum (2021) with title "How to fix the gender pension gap."
} 
However, this differential treatment of women has been increasingly challenged by policy makers who advocate gender neutrality. At the EU level, Directive 2006/54/EC (following Directive 96/97/EC), promoting equal treatment in social security schemes and prohibiting (gender) discrimination, reduces the possibility to redistribute from men to women. Specifically, the Directive's Chapter 2, article 9, states that "Provisions contrary to the principle of equal treatment shall include those based on sex, either directly or indirectly, [...] for fixing different retirement ages [...] and setting different conditions for the granting of benefits." Following the Directive, all Member States reduced gender difference in retirement ages and pension benefits. Some countries fully implemented gender equality of pensionable ages (Austria, Belgium, Denmark and Germany, among others); some other countries apply derogations in accordance with Article 141(4) of the Treaty and continue to compensate for women for the time they spent raising children (for example Bulgaria, France, Italy, Lithuania, Slovenia). ${ }^{3}$

The EU Directive takes for granted that women should be the target of redistribution. However, as our analysis will show, redistribution from men to women is not always optimal. In the debate on pension reforms, European policy makers seem to neglect two important facts: first, women live longer and, second, spouses may pool their resources. In couples, redistribution is already carried out in a spontaneous way, and it benefits the low-income spouse, typically the woman.

Despite the relevance of this subject and the ongoing debates about pension reforms in many Member States, the underlying gender issues have received very little attention. Consequently, some fundamental questions are currently not well understood. This is a serious omission because these problems are crucial in an aging society, where gender equality is becoming a key concern. Specifically, there is little guidance to what would be the appropriate "direction" and extent of redistribution between men and women in a society where women live longer but have lower labor incomes. Bommier et

\footnotetext{
${ }^{3}$ DIRECTIVE 2006/54/EC states that "[... the principle of equal treatment does not prevent Member States from maintaining or adopting measures providing for specific advantages in order to make it easier for the under-represented sex to pursue a vocational activity or to prevent or compensate for disadvantages in professional careers. Given the current situation and bearing in mind Declaration No 28 to the Amsterdam Treaty, Member States should, in the first instance, aim at improving the situation of women in working life."
} 
al. (2011a) provide some partial insights by studying pension design when individuals differ in lifespans. However, they assume that all individuals have the same earning opportunities which means that their analysis cannot directly be applied to gender issues where the wage gap is significant. Pestieau and Racionero (2016) also abstract from wage differences and study pension design under longevity differences that are explained by job harshness (which translates into differences of the probability of a premature death). Fleurbaey et al (2016) analyze the optimal retirement policy when individuals differ in their income and longevity but assume that longevity and productivity are positively correlated, a case that does not reflect the gender differences observed in reality. Furthermore, neither of these papers accounts for the possibility that individuals may form couples and pool their resources.

Another open question concerns the implication of "equal treatment" rules requiring gender neutrality of the pension scheme. Though appealing from a "horizontal equity" perspective, this is similar to "no tagging" conditions which have been studied in the optimal taxation literature; see for instance Cremer et. al (2012a). Imposing gender neutrality in a society where men and women differ in crucial characteristics like life expectancy and earning opportunities necessarily reduces overall welfare. But an interesting open question is how this requirement affects pension design, the induced allocation and particularly gender gaps in retirement ages and the extent of redistribution. In different words, it is not immediately obvious how the different groups (identified by gender and marital status) will be affected. ${ }^{4}$

Our analysis aims at improving our understanding of these issues. We assume that men and women choose their consumption and retirement ages given the pension scheme. We determine the pension scheme that maximizes welfare accounting for individual's

\footnotetext{
${ }^{4}$ Gender neutrality and other non-discrimination rules are common in insurance markets and in regulated industries. In private (imperfectly competitive) markets these rules are not necessarily inefficient. However, in the case of insurance policies, they amount to introducing adverse selection in markets which would otherwise yield actuarially fair contracts (and full insurance). Finkelstein et al. (2009) for instance, study the efficiency cost and the redistributive impact of banning gender specific annuity pricing in the UK. While their exercise bears some similarities with our paper it differs in several crucial aspects. In particular, they consider private markets where adverse selection brings about Rothschild and Stiglitz or similar types of equilibria while we consider retirement schemes where the objective is redistribution. In addition, they do not consider couples.
} 
decisions. Women live longer than men but have lower earning opportunities. Gender and retirement ages are publicly observable, while individual consumption levels are not. This constraint is irrelevant when there are only singles, but it imposes a restriction with couples because the allocation of resources between spouses cannot be controlled. The solutions we refer to as first best (FB) is then effectively a constrained FB.

A "pension scheme" in our setting is characterized by the total transfer, including net pension benefits and payroll taxes, assigned to an individual or couple. ${ }^{5}$ Individuals are the target of redistribution when their total pension transfer is positive, that is, when their contribution is lower than the received benefit. For instance, when men are net contributors while women are net recipients the pension system redistributes from men to women.

In the first part, we study the desirable direction of gender redistribution for singles and for couples. When individuals differ in their lifespans the definition of social welfare is both crucial and not trivial. A simple utilitarian welfare function fails to capture the possible concern for redistribution between long-lived and short-lived individuals. Indeed, it effectively puts a higher weight on the longer lived since their instantaneous utilities are added over more period. The specification of welfare we use is inspired by Bommier et al. (2011a). Social welfare is utilitarian in that it is additive and puts the same weight on all individuals. However, the sum is taken over an increasing concave transformation of individuals' lifetime utilities. The concave transformation reflects society's aversion towards multiperiod inequality (Atkinson and Bourguignon, 1982, and Gottschalk and Spolaore, 2002) or risk aversion with respect to the life duration (Bommier, 2006). ${ }^{6}$

The first question we address is the following: what is the optimal direction of gender redistribution under the double gap in longevity and earnings? We show that the answer depends on the government's degree of lifespans inequality aversion and on whether individuals are singles or live in couple. Note that redistribution from single

\footnotetext{
${ }^{5}$ This is merely a matter of implementation; see Cremer et al. (2004) for more details.

${ }^{6}$ The limitations of classical utilitarianism when individuals differ in lifespans are also discussed by Leroux and Ponthière (2013).
} 
men to single women implies that women receive a pension benefit which exceeds their contributions while the opposite is true for men. However, because of the consumption pooling, redistribution between partners in a couple can only be achieved via the retirement age.

In the first best with singles, optimal redistribution goes from men to women if lifespans inequality aversion is sufficiently low. For high value of lifespans inequality aversion, redistribution may be reversed but the possibility that there continues to be redistribution from men to women cannot be ruled out even in the Rawlsian case when earnings are sufficiently different. Turning to couples, lifespans inequality aversion has a "more drastic" impact on redistribution than in the singles case. When inequality aversion is sufficiently high, optimal redistribution is always from women to men, so that women retire later than their partners, irrespective of the size of the wage gap.

In the second part, we introduce gender neutrality so that pension schemes cannot be explicitly conditioned (tagged) on gender. Formally this amounts to imposing a selfselection constraint: the government will offer a menu of incentive compatible pension schemes and men and women will choose the preferred one. The solution then introduces some distortions in retirement ages that depend on the pattern of binding incentive constraints. Adding the gender neutrality constraint necessarily reduces welfare and the extent of gender redistribution, however its specific impact on the pension scheme and on the retirement age of singles and couples is not obvious.

With singles only, incentive compatibility requires a (downward or upward) distortion in the retirement age of the gender, male or female, that represents the target of redistribution. When all individuals live in couples, the first best can be implemented by a gender neutral pension system as long it implies a lower retirement age for the wife. However, a solution in which women retire later than men can no longer be implemented. Consequently, when inequality aversion is sufficiently high, the gender neutral solution implies equal retirement ages. In that case, gender neutrality restricts the possibility to compensate men for their shorter life and for pooling their resources.

Our theoretical analysis is completed by numerical simulations based on a calibrated model. It shows which of the cases discussed are likely to arise with empirically relevant 
parameter values, and provides an estimation of the direction and size of pension transfers, both marginal and total. Simulations allow us to quantify the size of the welfare cost on the different segments of the population: male and female singles and spouses. Results indicate that, even for high levels of inequality aversion, the optimal direction of redistribution remains from single men to single women. In the case of couples, gender neutrality negatively affects men.

Finally, in the numerical simulations, we also consider the more realistic case where singles and couples coexist. Since the policy can be conditioned on the marital status (there is tagging to this respect), this won't affect the qualitative results obtained within each group. However, there is now a global budget constraint, allowing for cross subsidies among single individuals and married individuals. We show that previous results are confirmed and, in the mixed economy too, gender neutrality impairs single women and male spouses while it benefits single men. Focusing on overall redistribution with men and women irrespective of their marital status, the desirable direction of redistribution remains from men to women, unless inequality aversion is extremely high. Again, the burden of gender neutrality falls on single women and married men; specifically, married men end up being net contributors instead of net recipients.

\section{The Model}

Preferences over consumption $c$ and labor $\ell$, of an individual of age $t$ can be expressed by an instantaneous utility function $V(t)$ assumed to be additively separable:

$$
V(t)=u(c(t))-r(t) \ell(t)
$$

where $r(t)$ represents the instantaneous intensity of labor disutility. Utility of consumption $u(c)$ is strictly increasing and concave, while $r(t)$ is an increasing function so that disutility of labor increases with age, reflecting for instance a declining health status.

This specification is inspired by Cremer et al. (2004). A main difference is that here we concentrate on labor supply at the extensive margin using the following restriction: $\ell \in\{0,1\}$. As in their model, we assume that the instantaneous wage rate $w(t)$ is 
constant over time. ${ }^{7}$ At any moment in time, individuals can either work a given number of hours, normalized to one, or not work at all, that is retire. Given that $r(t)$ is increasing and wages are constant over time, $V(t)$ can be rewritten as

$$
\begin{aligned}
V(t) & =u(c(t))-r(t) & & \text { if } t \leq \tau \\
& =u(c(t)) & & \text { if } t>\tau,
\end{aligned}
$$

where $\tau$ denotes the retirement age, i.e. the length of working life.

Let date 0 denote entrance to the labor force, and $T$ the maximum lifespan. The interest rate and the discount factor are constant, equal and normalized to 0. Lifetime utility is therefore given by

$$
U=\int_{0}^{T} V(t) d t=\int_{0}^{T} u(c(t)) d t-\int_{0}^{\tau} r(t) d t
$$

Separability between utility from consumption and disutility from labor, concavity of the instantaneous utility function, perfect capital markets, certain lifetimes and constant wages over time all together imply that individuals will set their level of consumption equal in all periods. Consequently, lifetime utility can be rewritten as

$$
U=T u(c)-R(\tau)
$$

where $R(\tau)=\int_{0}^{\tau} r(t) d t$ is the lifetime disutility from labor.

We consider a population with men and women born in equal proportions. Individuals may remain single or form couples. In the analytical part, we concentrate on the cases where all individuals are singles or where they all live in couples. The results would not change if both types of living arrangements were to coexist, as long as the policy can be tagged on the marital status. We illustrate this case through a numerical example in Section 6.

Throughout the paper we concentrate on a single generation in the steady state with a stationary population. Since the population growth rate and the interest rate are equal, in the model funded and pay-as-you-go pension systems are equivalent.

\footnotetext{
${ }^{7}$ See Ndiaye (2022) for a model with uncertainty in the wage rate and endogenous retirement. The author, however, does not consider differences in lifespan.
} 
Singles. Utility of a single individual of gender $j=f, m$, female or male, is given by ${ }^{8}$

$$
U_{j}^{s}\left(c_{j}, \tau_{j} ; T_{j}\right)=T_{j} u\left(c_{j}\right)-R\left(\tau_{j}\right)
$$

Given retirement age $\tau_{j}$, an individual's lifetime labor income is $w_{j} \tau_{j}$, where $w_{j}$ is the wage. Recall that women currently earn on average $15 \%$ less than men and live on average 4 to 6 years longer. ${ }^{9}$ Consequently, we assume that

Assumption 1: $w_{f} \leq w_{m}$ and $T_{f} \geq T_{m}$

To concentrate on redistribution across genders we assume that each group is homogenous: all men are characterized by the same wage and lifespan and the same for women.

Note that the double gap in longevity and earnings is taken as given in our model. Our setting is thus agnostic about the reasons explaining the gender gap in earnings. See the Conclusion for a discussion about persisting labor market frictions that penalize women, and labor market policies and pension schemes possibly addressing them.

Couples. We assume that couples are unitary and maximize the sum of spouses' utilities, so that they pool their resources. The utility of a couple is thus given by

$$
U^{c}\left(c_{f}, c_{m}, \tau_{f}, \tau_{m} ; T_{f}, T_{m}\right)=T_{f} u\left(c_{f}\right)+T_{m} u\left(c_{m}\right)-R\left(\tau_{m}\right)-R\left(\tau_{f}\right)
$$

We assume throughout the paper that a couples' allocation of consumption across spouses is not publicly observable. Consequently, couples will always allocate their resources $I^{c}$ so as to maximize $T_{f} u\left(c_{f}\right)+T_{m} u\left(c_{m}\right)$ subject to $T_{f} c_{f}+T_{m} c_{m}=I^{c}$, which implies $c_{f}=c_{m}=c$. In other words, spouses' instantaneous consumption levels are always equalized. This assumption also applies to the allocation referred to as FB and

\footnotetext{
${ }^{8}$ Both women and men in the EU can expect to live in good health until the age of 64 (European Institute for Gender Equality, 2019). Given that no specific gender gaps in health are observed for individuals in working age, we assume that the function $R(\cdot)$ is the same for both genders; see also Britton and French (2020).

${ }^{9}$ Longevity and income are positively correlated and the gender gap in longevity decreases with education and other socioeconomic characteristics (Bohàcek et al, 2021). Sheshinski and Caliendo (2021) study the design of a progressive pension system when individuals with larger income also live longer. They disregard gender gaps and the direction of desirable redistribution is obvious in their case: from high-income/long-lived individuals to low-income/short-lived ones.
} 
which is thus, effectively, a constrained FB. This allocation is the relevant benchmark to infer the direction of optimal redistribution and to assess the second-best allocation achieved under gender neutrality. In particular the incentive constraint (if any) that is violated at the $\mathrm{FB}$ will of course be the one that is binding in the second best.

\section{The laissez-faire}

\subsection{Retirement decision of singles}

Singles choose lifetime consumption, $c_{j}^{s}$, and retirement age, $\tau_{j}^{s}$, where $j=f, m$, to maximize (4) under the budget constraint

$$
T_{j} c_{j}^{s}=w_{j} \tau_{j}^{s}
$$

where the superscript $s$ refers to "single". Substituting $c_{j}^{s}=w_{j} \tau_{j}^{s} / T_{j}$ into (4), the objective function can be rewritten as:

$$
T_{j} u\left(\tau_{j}^{s} w_{j} / T_{j}\right)-R\left(\tau_{j}^{s}\right)
$$

The FOC with respect to $\tau_{j}^{s}$ is:

$$
w_{j} u^{\prime}\left(c_{j}^{s}\right)-R^{\prime}\left(\tau_{j}^{s}\right)=0
$$

Men and women differ in wages and in their lifespan. To compare their retirement ages we have to study the impact of these two variables. From (7):

$$
\frac{d \tau_{j}^{s}}{d T_{j}}=\frac{w_{j}^{2}}{T_{j}^{2}} \frac{u^{\prime \prime}\left(c_{j}^{s}\right)}{\mathrm{SOC}}>0
$$

where

$$
\mathrm{SOC}=\left(\frac{w_{j}^{2}}{T_{j}} u^{\prime \prime}\left(c_{j}^{s}\right)-R^{\prime \prime}\left(\tau_{j}^{s}\right)\right)<0,
$$

is the second-order condition. In words, when two single individuals have the same wage, the one with a longer lifespan will retire later.

While the effect of $T$ is simple and unambiguous, the wages have a more complex impact on retirement. Differentiating (7) yields

$$
\frac{d \tau_{j}^{s}}{d w_{j}}=-\frac{u^{\prime}\left(c_{j}^{s}\right)+c_{j}^{s} u^{\prime \prime}\left(c_{j}^{s}\right)}{\mathrm{SOC}}=\frac{c_{j}^{s} u^{\prime \prime}\left(c_{j}^{s}\right)}{\operatorname{SOC}}\left(\varepsilon\left(c_{j}^{s}\right)-1\right),
$$


where $\varepsilon\left(c_{j}^{s}\right)$ is the intertemporal elasticity of substitution of individual $j$. Recall that, from Assumption $1, T_{f} \geq T_{m}$ and $w_{f} \leq w_{m}$. In addition, from (8), $d \tau_{j} / d T_{j}>0$. Two cases are then possible:

$$
\begin{aligned}
& \varepsilon\left(c_{j}^{s}\right)>1 \Rightarrow \frac{d \tau_{j}^{s}}{d w_{j}}>0 \quad \text { and } \quad \tau_{f}^{s *} \lessgtr \tau_{m}^{s *}, \\
& \varepsilon\left(c_{j}^{s}\right) \leq 1 \Rightarrow \frac{d \tau_{j}^{s}}{d w_{j}} \leq 0 \quad \text { and } \quad \tau_{f}^{s *}>\tau_{m}^{s *}
\end{aligned}
$$

In words, there is an income effect and a substitution effect. When the intertemporal elasticity of substitution is smaller than 1, women always retire later than men in the laissez-faire (LF). However, when the intertemporal elasticity of substitution is larger than 1 then (8) and (9) are of opposite sign, and the comparison between retirement ages is ambiguous and depends on which effect prevails. This in turn depends on the relative magnitudes of the longevity and the wage gaps. The case where women retire later is more likely to occur when the longevity gap is relatively large, whereas men are more likely to retire later when it is small.

Male and female consumption levels are most easily compared when $\tau_{f}^{s *}<\tau_{m}^{s *}$. In that case, it follows directly from the budget constraint (6) together with Assumption 1 that $c_{m}^{s *}>c_{f}^{s *}$. The single woman has a lower lifetime income and lives longer so that her consumption level must be lower. Interestingly, we obtain a lower consumption for women even when $\tau_{f}^{s *}>\tau_{m}^{s *}$. From (7), we have

$$
\frac{R^{\prime}\left(\tau_{f}^{s}\right)}{w_{f}}=u^{\prime}\left(c_{f}^{s}\right)>u^{\prime}\left(c_{m}^{s}\right)=\frac{R^{\prime}\left(\tau_{m}^{s}\right)}{w_{m}},
$$

implying again $c_{m}^{s *}>c_{f}^{s *}$.

Intuitively, women's higher longevity implies spreading resources over a longer period of time, which increases marginal utility of consumption. As a result, when wages are equal, women will work more or retire later than men. However, the higher men's wage has two opposite effects on labor supply: it increases the return of working an extra year (substitution effect), but it decreases the value of working by increasing average consumption (income effect). When $\varepsilon\left(c_{j}^{s}\right) \leq 1$, the income effect dominates and, keeping the lifespan constant, men tend to work less (retire earlier) than women. Here both the comparative statics of the wage and that of the lifespan go in the same direction and 
men indeed choose to retire earlier than women. But women's longer working life is not enough to reverse the ranking of consumption levels: women still consume less than men. When instead $\varepsilon\left(c_{j}^{s}\right)>1$, the substitution effect prevails and, keeping the lifespan constant, men tend to work more (retire later) than women. Now comparative statics of the wage and of the lifespan go in opposite directions and the ranking of retirement ages is ambiguous. The ranking of consumption levels of course remains the same with $c_{m}^{s *}>c_{f}^{s *}$.

\subsection{Retirement decision of couples}

Couples choose lifetime consumptions, $c_{f}^{c}$ and $c_{m}^{c}$, and retirement ages, $\tau_{f}^{c}$ and $\tau_{m}^{c}$, to maximize (5) subject to the budget constraint

$$
T_{f} c_{f}^{c}+T_{m} c_{m}^{c}=w_{f} \tau_{f}^{c}+w_{m} \tau_{m}^{c}
$$

where the superscript $c$ refers to "couple". The solution implies $c_{f}^{* c}=c_{m}^{c *}=c^{c *}$ and

$$
\begin{aligned}
& w_{m} u^{\prime}\left(c^{c *}\right)=R^{\prime}\left(\tau_{m}\right), \\
& w_{f} u^{\prime}\left(c^{c *}\right)=R^{\prime}\left(\tau_{f}\right),
\end{aligned}
$$

so that $\tau_{m}^{c *}>\tau_{f}^{c *}$. As anticipated after expression (5), the couple's disposable income is equally shared between spouses, but men retire later than their partners. ${ }^{10}$ Hence, we observe cross-subsidies (or redistribution) from men to women living in couple. ${ }^{11}$

The results obtained so-far are summarized in the following proposition.

Proposition 1 (Laissez-faire) 1) Single women always consume less than single men $\left(c_{f}^{s *}<c_{m}^{s *}\right)$.

2) When $\varepsilon\left(c_{j}^{s}\right) \leq 1$, single women retire later $\left(\tau_{f}^{s *}>\tau_{m}^{s *}\right)$ than single men. When $\varepsilon\left(c_{j}^{s}\right)>1$, single women may retire later or earlier than single men $\left(\tau_{f}^{s *} \lessgtr \tau_{m}^{s *}\right)$.

\footnotetext{
${ }^{10}$ All women are employed in our model. Housewives could be incorporated by letting $w_{f}$ tend to zero, which would imply a corner solution for the retirement age of female spouses.

${ }^{11}$ The assumption that spouses enter the labor market at the same age implies that they have the same age. Differences in spouses' age can be incorporated in the model by changing the longevity gap. Specifically, an increase in the longevity gap would capture the situation in which female spouses are younger than their partners.
} 
3) A couple's disposable income is equally shared between partners $\left(c_{f}^{c *}=c_{m}^{c *}=c^{c *}\right)$, but men retire later than their spouses $\left(\tau_{m}^{c *}>\tau_{f}^{c *}\right)$. This implies that redistribution from men to their spouses spontaneously emerges in the couple.

\section{First best}

The government maximizes the following social welfare function:

$$
S W=\varphi\left(U_{f}\right)+\varphi\left(U_{m}\right),
$$

where $\varphi$ is an increasing and concave function. For example, social welfare can be specified as

$$
S W=\frac{1}{1-\nu} \sum_{j}\left(U_{j}\right)^{1-\nu} ; j=f, m .
$$

In this specification $\nu$ measures the degree of concavity of $\varphi$. A larger level of $\nu$ implies a larger degree of inequality aversion. Special cases include the traditional utilitarian solution (linear $\varphi$ ) for $\nu=0$, and a Rawlsian welfare function for $\nu \rightarrow \infty$. When $\varphi$ is linear we return to an utilitarian welfare and there is no concern for redistributing between individuals of different lifespans. The only redistributive concern is the one across income levels which is brought about by the concavity of $U$.

As explained by Bommier et al. (2011a), a concave transformation of individual life cycle utility can be interpreted as aversion to multiperiod inequality, which explicitly refers to preferences of the social planner. Another interpretation is that we assume some risk aversion with respect to life duration that is reflected in individual preferences. In our setting the second interpretation is relevant even though there is not uncertainty in individual choices. Uncertainty about life duration is nevertheless relevant for the social welfare function which can be seen as the objective function of an individual "beyond the veil of ignorance". At that point gender and thus the lifespan is uncertain. ${ }^{12}$

A strictly concave $\varphi$ makes compensating shorter-lived individuals desirable. However, the trade-off between inequality in lifespans and inequality in labor earnings implies

\footnotetext{
${ }^{12}$ Redistribution between agents having the same endowment but with uncertain lifespans and preferences exhibiting risk aversion toward such uncertainty has been studied in Bommier et al (2011b). Introducing this uncertainty seriously complicates the model but, as in our paper, they show that redistribution heavily depends upon the individuals' degree of risk aversion toward uncertainty in lifespans.
} 
that the optimal direction of redistribution across genders (from men to women or the opposite) is not obvious. Because of the conflicting effects brought about by this double gender gap, the study of the first best (FB) is interesting for its own sake. It shows that the results of Bommier et al. (2011a) need to be qualified and may be reversed if a richer setting is considered. In addition, it will become clear below that the FB is a crucial reference for the study of the gender neutral solution.

Below, we first characterize the optimal allocation for singles and then for couples. As a remark before deriving the optimal allocations, note that the resource constraint is imposed for the considered generation. Since the economy is stationary and the population growth and the interest rate are both zero, this is equivalent to imposing a "per period" budget constraint in an overlapping generations model.

\subsection{Singles}

\subsubsection{Allocation}

To determine the optimal allocation the social planner maximizes social welfare defined by (10) with respect to each gender's consumption levels and retirement ages $\left(c_{j}^{s}, \tau_{j}^{s}\right), j=$ $f, m$. Notably, the solution implicitly defines net pension levels which are given by $P_{j}=T_{j} c_{j}-w_{j} \tau_{j}$. The Lagrangian expression associated with the maximization of social welfare is given by

$$
\begin{aligned}
\mathcal{L} & =\varphi\left[T_{f} u\left(c_{f}^{s}\right)-R\left(\tau_{f}^{s}\right)\right]+\varphi\left[T_{m} u\left(c_{m}^{s}\right)-R\left(\tau_{m}^{s}\right)\right] \\
& +\mu\left[w_{f} \tau_{f}^{s}+w_{m} \tau_{m}^{s}-T_{f} c_{f}^{s}-T_{m} c_{m}^{s}\right] .
\end{aligned}
$$

Rearranging the FOCs, presented in Appendix A.1, yields

$$
\begin{aligned}
& \frac{R^{\prime}\left(\tau_{j}^{s F B}\right)}{u^{\prime}\left(c_{j}^{s F B}\right)}=w_{j} \text { for } j=f, m, \\
& u^{\prime}\left(c_{f}^{s F B}\right) \varphi^{\prime}\left(U_{f}^{s F B}\right)=u^{\prime}\left(c_{m}^{s F B}\right) \varphi^{\prime}\left(U_{m}^{s F B}\right) .
\end{aligned}
$$

We prove the following Proposition in Appendix A.2.

Proposition 2 (FB allocation with singles) The first-best allocation is described by (13) and (14) and always implies $U_{f}^{s F B} \geq U_{m}^{s F B}$ and $c_{m}^{s F B} \geq c_{f}^{s F B}$. 
(i) When $\varphi$ is linear, we have $c_{f}^{s F B}=c_{m}^{s F B}$ and $\tau_{f}^{s F B} \leq \tau_{m}^{s F B}$.

(ii) When $\varphi$ is Rawlsian, we have $\tau_{f}^{s F B}>\tau_{m}^{s F B}$ if $w_{m}=w_{f}$ and $T_{f}>T_{m}$.

(iii) When $\varphi$ is Rawlsian we have $\tau_{f}^{s F B}<\tau_{m}^{s F B}$ if $w_{m}>w_{f}$ and $T_{f}=T_{m}$.

Two general properties emerge from the first-best allocation. First, women always benefit from a higher life cycle utility than men (except of course in the case where $\varphi$ is Rawlsian in which case $U_{f}^{s F B}=U_{m}^{s F B}$ ). Second, men always benefit from a per-period consumption that is at least as large as that of women. The implications of these results for the redistribution across gender will become clear in the next subsection where we study the implementation via a pension system.

\subsubsection{Implementation}

Rather than controlling both $c$ (or equivalently $P$ ) and $\tau$, the optimal allocation can be implemented via a net benefit functions $P_{j}\left(\tau_{j}\right)$. In other words, when the net pension as a function of retirement age $P_{j}\left(\tau_{j}\right)$ is appropriately designed, the optimal allocation is decentralized by letting individuals choose their retirement ages.

Functions $P_{j}\left(\tau_{j}\right)$ are interesting for two reasons. First, their level and more specifically their sign determines which of the genders benefits from redistribution. Since the budget constraint implies $P_{f}+P_{m}=0$ (total net benefits must be zero), $P_{f}$ and $P_{m}$ must be of opposite signs. For instance, $P_{f}^{F B}>0>P_{m}^{F B}$ implies redistribution from men to women. In words, women receive pension benefits exceeding their overall contributions while the opposite occurs for men. Second their derivatives $P_{j}^{\prime}$ (marginal benefit) show if and how retirement decisions are distorted. ${ }^{13}$

Given the net benefit function $P_{j}\left(\tau_{j}\right)$, singles choose $c_{j}$ and $\tau_{j}$ to maximize

$$
T_{j} u\left(c_{j}\right)-R\left(\tau_{j}\right)
$$

subject to

$$
w_{j} \tau_{j}+P_{j}\left(\tau_{j}\right)-T_{j} c_{j}=0
$$

The FOC implies

$$
\frac{R^{\prime}\left(\tau_{j}\right)}{u^{\prime}\left(c_{j}\right)}=w_{j}+P_{j}^{\prime}\left(\tau_{j}\right)
$$

\footnotetext{
${ }^{13}$ In other words, they are the counterpart to marginal tax rates in an optimal tax model.
} 
Comparing (15) and (13), one observes that implementing the FB allocation requires $P^{\prime}\left(\tau_{j}\right)=0$. Hence, the pension scheme is "flat" in the sense that there is no marginal distortion of the individual pension decision.

The level of $P_{j}^{F B}$ then follows from the individual budget constraint:

$$
\begin{aligned}
& P_{f}^{F B}=T_{f} c_{f}^{F B}-w_{f} \tau_{f}^{F B}, \\
& P_{m}^{F B}=T_{m} c_{m}^{F B}-w_{m} \tau_{m}^{F B} .
\end{aligned}
$$

We are now in a position to discuss the redistributive implications of Proposition 2. When $\varphi$ is linear, the government is only concerned about redistribution between agents with different yearly labor income. As a result, both men and women receive the same consumption level and women retire earlier (point $(i)$ of Proposition 2). Since women live longer, this implies redistribution from men to women so that $P_{f}^{s F B}>0>P_{m}^{s F B}$.

Consider now the case where $\varphi$ is strictly concave so that the government is also concerned about redistribution from long to short-lived agents. When wages are equal $\left(w_{f}=w_{m}\right)$, we return to the setting considered by Bommier et al. (2011) and we know from (14) that $c_{f}^{s F B}<c_{m}^{s F B}$ as soon as $\varphi$ is strictly concave; so that it certainly holds under the Rawlsian welfare function $S W=\min \left[U_{f}, U_{m}\right]$. From equation (13), the Rawlsian solution with $U_{f}^{c F B}=U_{m}^{c F B}$ implies $\tau_{f}^{s F B}>\tau_{m}^{s F B}$ (point (ii) of Proposition 2). Consequently the Rawlsian solution requires $P_{f}^{s F B}<0<P_{m}^{s F B}$. This shows that when wages are equal the direction of redistribution is effectively reversed at the Rawlsian solution. By continuity this property continues to hold when $\varphi$ is sufficiently concave. Similarly it continues to hold when yearly incomes are not too different. But when $w_{f}$ is much smaller than $w_{m}$, we can no longer conclude. In that case, even in the Rawlsian solution, $P_{f}^{s F B}>0>P_{m}^{s F B}$ cannot be ruled out: in point (iii) of Proposition 2 the direction of redistribution is ambiguous because $T_{m}=T_{f}$ and $T_{f} c_{f}^{F B}-w_{f} \tau_{f}^{F B}$ $\gtrless T_{m} c_{m}^{F B}-w_{m} \tau_{m}^{F B}$. Note that $P_{f}^{s F B}>0>P_{m}^{s F B}$ is necessarily true when $w_{f}$ is close to zero while $w_{m}$ is sufficiently large. These results are summarized in the following proposition.

Proposition 3 (FB pensions with singles) With a utilitarian $S W$ function redistribution from men to women is always optimal. If the $S W$ function is sufficiently concave, 
redistribution may be reversed. However, the possibility that redistribution from men to women remains optimal cannot be ruled out, even in the Rawlsian case, when the wage gap is sufficiently high.

\subsection{Couples}

We now turn to the case where all individuals live in couples. As mentioned above, we characterize a constrained FB in which couples pool their consumption so that $c_{f}^{c}=c_{m}^{c}=c^{c} .{ }^{14}$ As mentioned before, since spouses pool their resources, redistribution within a couple can only be achieved via the retirement age.

The social planner solves

$$
\max _{c^{c}, \tau_{f}, \tau_{m}} S W=\varphi\left(T_{f} u\left(c^{c}\right)-R\left(\tau_{f}\right)\right)+\varphi\left(T_{m} u\left(c^{c}\right)-R\left(\tau_{m}\right)\right),
$$

subject to

$$
w_{m} \tau_{m}+w_{f} \tau_{f}-\left(T_{f}+T_{m}\right) c^{c}=0 .
$$

When $\varphi$ is linear we return to the solution with singles and

$$
\begin{aligned}
& c_{f}^{c F B}=c_{m}^{c F B}=c^{c F B} ; \\
& \tau_{f}^{c F B}<\tau_{m}^{c F B} .
\end{aligned}
$$

Thus, we have redistribution from men to women and the female spouse is better off. Note that, unlike in the singles case, the FB coincides here with the laissez-faire. The equalization of consumption levels, which in the singles case required transfers, is spontaneously achieved with couples because they pool their resources. ${ }^{15}$

When $\varphi^{\prime \prime}<0$ the solutions with singles and couples differ. This follows because couples pool their incomes so that $c_{f}^{c}=c_{m}^{c}=c^{c}$ applies by definition, while consumption levels will in general differ for singles. Formally, this is as if we impose an extra constraint

\footnotetext{
${ }^{14}$ This assumption is made to concentrate on pension design. The unrestricted FB would in general require different consumption levels. However, since couples pool their resources, this solution can only be implemented when benefits are conditioned not just on retirement ages but also on spouses' consumption levels. In other words, the pension system would have to be associated with an implicit or explicit tax on spouses' consumption levels. But this is ruled out by our assumption that the allocation of disposable income within a couple is not publicly observable.

${ }^{15}$ And in this case our constrained FB is effectively the same as the unrestricted FB, given that the latter requires equal consumption levels anyway.
} 
so that social welfare with couples will be lower. It also means that the results of Bommier et al. (2011a) no longer apply even when $w_{f}=w_{m}$.

We show in Appendix A.4 that $U_{f}^{c F B} \geq U_{m}^{c F B}$ always holds irrespective of the degree of concavity of $\varphi$. But this does not tell us anything about the spouses' retirement ages. Recall that in the laissez-faire and in the FB with linear $\varphi$, women always retire earlier than man. We now examine if we can have $\tau_{f}>\tau_{m}$ when $\varphi$ is sufficiently concave. The interesting result is that, with couples, the Rawlsian solution entailing $U_{f}^{c F B}=U_{m}^{c F B}$ implies immediately that $\tau_{m}^{c F B}<\tau_{f}^{c F B}$. This was not necessarily true with singles only but, since spouses pool their incomes and women live longer, utility levels can now be equalized only when men retire earlier. By continuity $\tau_{m}^{c F B}<\tau_{f}^{c F B}$ also obtains when $\varphi$ is sufficiently concave. To sum up, in the case with couples only, we can say for sure that the ranking of gender retirement ages is reversed when $\varphi$ is sufficiently concave.

These results are summarized in the following proposition.

Proposition 4 (FB allocation with couples) A first-best allocation is described by (A.5) and (A.6).

(i) It always implies $U_{f}^{c F B} \geq U_{m}^{c F B}$ irrespective of the degree of concavity of $\varphi$.

(ii) When $\varphi$ is linear, we have $\tau_{f}^{c F B}<\tau_{m}^{c F B}$; but $\tau_{f}^{c F B}>\tau_{m}^{c F B}$ always obtains when $\varphi$ is sufficiently concave.

\subsubsection{Implementation}

In the case of singles, we have concentrated on the sign of the net pensions $P_{f}^{s}\left(\tau_{f}^{s}\right)$ and $P_{m}^{s}\left(\tau_{m}^{s}\right)$ because this showed the direction in which the system redistributes. With couples only, the levels of the pensions are no longer relevant for the redistribution across spouses. Recall that couples pool their resources and their total net pension is by definition always equal to zero (see below). Hence, with couples only, redistribution can only take place via the retirement ages. Furthermore, as long as $P_{f}^{c}+P_{m}^{c}=0$ (in equilibrium) their levels can set arbitrarily. For instance one can set $P_{f}^{c}\left(\tau_{f}^{c F B}\right)=$ $P_{m}^{c}\left(\tau_{m}^{c F B}\right)=0$, which intuitively means that the system is actuarially fair (benefits equal contributions for everyone). 
Note that, even in the laissez-faire, there is redistribution from men to women in the couple. But this is spontaneous and not explained by public policy. The same is true for the FB with linear $\varphi$ which, as mentioned before, corresponds to the LF. However, this redistribution cannot be attributed to the pension system (couples do it anyway). As a matter of fact, with a strictly concave $\varphi$ the pension system will always redistribute towards men with respect to the $L F$, because the policy will make the utilities levels less unequal. In other words, it mitigates the spontaneous redistribution operated within the couple. Overall, when $\varphi$ is not too concave, women will continue to spend more than they earn, but this is due to the resource pooling and not to the pension system. In other words the pension system should not necessarily reverse the redistribution towards women that occurs spontaneously within the couple. The lower wage always pleads for (overall) redistribution towards women, but its extent is mitigated because of differences in lifespan when welfare is concave.

With this in mind, we restrict ourselves to studying the derivatives of the net benefit functions $P_{j}^{c}\left(\tau_{j}^{c}\right)$, which mirror the distortion in retirement ages. In the case of singles they were all equal to zero in the FB; see comments below equation (15) in Section 4.1. In that case, redistribution could be performed via pension benefits (that is in cash) and there was no need to distort retirement decisions. For couples this is no longer true. In Appendix A.5 we show that the derivatives of the implementing net benefit function satisfy

$$
\frac{\partial P_{f}^{c F B}}{\partial \tau_{f}}>0>\frac{\partial P_{m}^{c F B}}{\partial \tau_{m}} .
$$

In words, when $\varphi$ is strictly concave, the pension scheme will induce the couple to increase the retirement age of the female spouse and decrease that of the male spouse. This is in line with the results presented above and particularly the property that when $\varphi$ is sufficiently concave we will have $\tau_{f}^{c F B}>\tau_{m}^{c F B}$. Intuitively the concave $\varphi$ calls for redistribution towards the shorter-lived male. Since consumption levels are equal, pension levels are ineffective for this purpose and the only way to mitigate the longevity effect is to increase female retirement age and decrease the male one. The following proposition summarizes the results: 
Proposition 5 (FB pensions with couples) (i) With a utilitarian $S W$ function, redistribution from men to women is not only optimal but also achieved in a decentralized way in the laissez-faire allocation. (ii) With a strictly concave $S W$ function, implementing the FB requires government intervention but, because of the couples' consumption pooling, redistribution can be achieved only by distorting retirement ages. (iii) With a strictly concave $\varphi$ the pension system will always redistribute towards men with respect to the LF, because the policy will make the utilities levels less unequal. (iv) This redistribution is achieved by decreasing the male retirement age and increasing that of women. (iv-a) When the transformation is not too concave, men continue to retire later than women. (iv-b) When the transformation is sufficiently concave, the ranking of gender retirement ages is reversed irrespective of the size of the wage gap.

\section{Gender neutrality}

As mentioned in the Introduction, according to Directive 2006/54/EC, social security schemes should treat men and women equally, in particular with regard to their pension benefits. So far we have assumed that the benefit scheme can be conditioned (tagged) on the gender. The optimal tax literature has shown that tagging, that is conditioning the transfer function on an exogenous and observable variable, is in general welfare improving; see Cremer et al. (2012a) and the references provided there. However, it may violate the principle of horizontal equity and thus be considered as unacceptable as it may imply more or less arbitrary discrimination.

The previous sections have shown that, when this is possible, differential treatment of genders is indeed optimal. We now examine how the solution would be affected if gender neutrality is imposed in the sense that tagging is no longer possible. This does not mean that men and women retire at the same age nor that they must obtain the same net benefits. It does mean, however, that they must be offered the same options. Consequently we do not rule out differentiation across genders but the allocation must be incentive compatible: the same menu of contracts must be offered to men and women who then self-select. In other words, gender neutrality effectively means that the policy 
has to be designed as if gender were not observable.

We look at contracts in the $(\tau, P)$ space because these are the observable variables. Per-period consumption $c$ 's is not observable or rather cannot be specified in the contract because this would violate gender neutrality. ${ }^{16}$ This is relevant for the writing of the incentive constraint because, while the mimicker has the same $P$ as the mimicked, he or she does not have the same consumption (because wages differ across genders).

It is reasonable instead to assume that pensions, gender neutrality notwithstanding, can be conditioned on marital status.

\subsection{Singles only}

Preferences for singles in the $(\tau, P)$ space are given by

$$
U_{j}^{s}=T_{j} u\left(\frac{w_{j} \tau_{j}^{s}+P_{j}^{s}}{T_{j}}\right)-R\left(\tau_{j}^{s}\right), \text { for } j=m, f
$$

Indifference curves in this space may not be monotonic even when they are increasing and convex in the $(\tau, c)$ space. ${ }^{17}$ To see that, note that the slope of an indifference curve in the $(\tau, P)$ space is the $M R S$ obtained by differentiation of (19):

$$
M R S_{j}=\left.\frac{d P_{j}}{d \tau_{j}}\right|_{U^{s}}=\frac{R^{\prime}\left(\tau_{j}\right)}{u^{\prime}\left(\frac{w_{j} \tau_{j}+P_{j}}{T_{j}}\right)}-w_{j}, \text { for } j=m, f .
$$

The first term on the RHS is the $M R S_{\tau c}$ in the $(\tau, c)$ space. When $\tau$ is small this $M R S_{\tau c}$ is small so that (20) is negative. But as $\tau$ increase the $M R S_{\tau c}$ increases and may eventually equal and exceed $w{ }^{18}$ Then (20) is positive and the indifference curve is U-shaped.

Intuitively, to remain indifferent, individuals who work for an extra year must be compensated by an amount given by $M R S_{\tau c}$ but their income increases by $w$. Consequently when the $M R S_{\tau c}$ is small (for small levels of $\tau$ ), their net pension can decrease but as $\tau$ increases the $M R S_{\tau c}$ increases and may eventually exceed $w$.

\footnotetext{
${ }^{16}$ Directly controlling individual consumption levels would bring us back to gender tagging as $c$ reveals $T$ and thus gender.

${ }^{17}$ Which corresponds to the standard textbook case of indifference curves in the labor supply and consumption space.

${ }^{18}$ This occurs for sure when indifference curves in the $(\tau, c)$ space satisfy the Inada conditions.
} 
Expression (20) also show that a general single-crossing property cannot be established. At any given point $(\tau, P)$ the first term on the RHS, namely the $M R S_{\tau c}$ is smaller for women (they have the smaller consumption) but $w_{f}$ which is subtracted is also smaller. Consequently the comparison of the full expression between men and women is ambiguous unless wages are equal or similar. ${ }^{19}$

\subsubsection{Optimal pensions under gender neutrality}

The optimal allocation is obtained by solving

$$
\begin{aligned}
\max _{P_{f}^{s}, P_{m}^{s}, \tau_{f}^{s}, \tau_{m}^{s}} & \varphi\left[T_{f} u\left(\frac{w_{f} \tau_{f}^{s}+P_{f}^{s}}{T_{f}}\right)-R\left(\tau_{f}^{s}\right)\right]+\varphi\left[T_{m} u\left(\frac{w_{m} \tau_{m}^{s}+P_{m}^{s}}{T_{m}}\right)-R\left(\tau_{m}^{s}\right)\right] \\
\text { s.t. } \quad & P_{m}^{s}+P_{f}^{s}=0, \\
& T_{f} u\left(\frac{w_{f} \tau_{f}^{s}+P_{f}^{s}}{T_{f}}\right)-R\left(\tau_{f}^{s}\right) \geq T_{f} u\left(\frac{w_{f} \tau_{m}^{s}+P_{m}^{s}}{T_{f}}\right)-R\left(\tau_{m}^{s}\right), \quad\left(\lambda_{f}^{s}\right) \\
& T_{m} u\left(\frac{w_{m} \tau_{m}^{s}+P_{m}^{s}}{T_{m}}\right)-R\left(\tau_{m}^{s}\right) \geq T_{m} u\left(\frac{w_{m} \tau_{f}^{s}+P_{f}^{s}}{T_{m}}\right)-R\left(\tau_{f}^{s}\right), \quad\left(\lambda_{m}^{s}\right)
\end{aligned}
$$

where $\lambda_{j}^{s}, j=f, m$, denotes the Lagrangian multiplier associated with the incentive compatibility constraint of type $j$.

We concentrate on the case where a single incentive constraint (IC) binds. As we mentioned above, the single-crossing property may not hold. Consequently it cannot be ruled out a priori that both ICs bind. However, it does not appear that this can occur in equilibrium. Roughly speaking, the binding incentive constraint is determined by the direction of redistribution in the FB. To see that, consider for instance the case where $\varphi$ is linear or not too concave. Here, redistribution from men to women is efficient and the binding IC constraint will be that of the man, i.e. $\lambda_{m}^{s}>0$. On the other hand, when $\varphi$ is sufficiently concave, the FB allocation may entail redistribution from women to men.

\footnotetext{
${ }^{19}$ Differentiating the expression for the $M R S,(20)$ yields

$$
\frac{\partial M R S}{\partial T}=\frac{c}{T} \frac{R^{\prime}(\tau) u^{\prime \prime}(c)}{\left(u^{\prime}(c)\right)^{2}}<0 .
$$

Consequently, when $w_{f}=w_{m}$, the two indifference curves cross only once at a point where $M R S_{f}<$ $M R S_{m}$.
} 
Hence, we would have $\lambda_{f}^{s}>0$ because the FB allocation now violates women's IC. In either case it is clear that the other IC constraint cannot also be binding. Furthermore, when we switch from one case to the other, we will have $P_{f}=P_{m}=0$; implying that no redistribution exists and none of the ICs is binding.

\subsubsection{Properties of the solution}

The formal results are reported in Proposition 9 which is stated and established in Appendix A.6. Here we restrict ourselves to an informal presentation of the results, focusing on their interpretation and implications for pension design.

From equation (15), the implementing pension rule must satisfy

$$
P_{j}^{\prime}\left(\tau_{j}^{s}\right)=\frac{R^{\prime}\left(\tau_{j}^{s}\right)}{u^{\prime}\left(\frac{w_{j} \tau_{j}^{s}+P_{j}^{s}}{T_{j}}\right)}-w_{j}=M R S_{j}^{s} .
$$

Proposition 9 in Appendix A.6 shows that the two opposite regimes can occur: $(i)$ when (24) is binding, so that we have $\lambda_{m}^{s}>0$ and $\lambda_{f}^{s}=0$, redistribution from men to women is optimal and men are the mimickers. (ii) Conversely, when (23) is binding with $\lambda_{m}^{s}=0$ and $\lambda_{f}^{s}>0$, redistribution from women to men is now desirable so that women become the mimickers. In each regime $(i)$ and (ii), either subcase (a) or subcase (b) occurs, entailing that women retire later or earlier than men, respectively.

Analytically not much can be said about the circumstances under which the subcases (a) or (b) occur but precise results can be obtained for specific functions and parameter values; see Section 6. However, we can study the occurrence of regimes $(i)$ and $(i i)$ considering the results obtained for the FB in Section (4.1) because, roughly speaking, the binding IC is determined by the direction of redistribution in the FB. In particular, from Proposition 3 we know that the FB allocation implies redistribution from single men to single women when the social welfare function is utilitarian. It thus follows that, when $\varphi$ is close to linear, we expect that (24) is binding. To see that this expectation is correct, let us denote by subscripts $m f$ and $f m$ mimicking individuals' consumption bundle; for instance $c_{m f}^{s}=\left(w_{m} \tau_{f}^{s}+P_{f}^{s}\right) / T_{m}$. Recall that, when $\varphi$ is linear, the FB allocation entails $c_{f}^{s F B}=c_{m}^{s F B}$ and $\tau_{f}^{s F B}<\tau_{m}^{s F B}$ (Proposition 2, part $(i)$ ), which implies $c_{m f}^{s} \geq c_{m}^{s F B}$. Hence, IC (24) is violated. By continuity this will remain true when $\varphi$ is 
not too concave. This case yields regime $(i)$ where the retirement decision of the male is not distorted, which is in line with the traditional "no distortion at the top" property. The retirement decision of the single women on the other hand is distorted. As usual in tax theory, the sign of the distortion hinges on the comparison of the MRS between mimicker and mimicked individuals. However, its determination is more complex than in the standard model. Since the indifference curves are not monotonic they may intersect in the increasing or the decreasing part and this determines which subcase of the regime applies, (a) or (b).

To sum up, in both subcases (a) or (b) of regime $(i)$, gender neutrality limits the possibilities of redistributing from single men to single women who may end up with a lower lifetime utility than men.

On the other hand, when $\varphi$ is sufficiently concave, redistribution absent gender neutrality may be reversed so that we would have regime (ii) with $\lambda_{m}^{s}=0$ and $\lambda_{f}^{s}>0$ because the FB allocation now violates the female incentive constraint. Then, the retirement decision of single men is distorted and more significantly, gender neutrality limits redistribution towards single men.

The bottom line is summarized by the following statement:

\section{Proposition 6 (Redistribution accross singles under gender neutrality) With}

singles only, gender neutrality hurts the gender towards whom redistribution is targeted at the first-best allocation.

Which gender is hurt by gender neutrality is mostly an issue of societal preferences, represented by $\varphi$, and an empirical question because, depending on the specification and parameter values, regime (ii) may never occur. Overall, the above discussion has made it clear that the most likely outcome is that gender neutrality hurts single women. As it will become clear in Section 6, this observation is confirmed by numerical simulations. 


\subsection{Couples only}

\subsubsection{Gender neutrality with couples}

We now return to the case where all individuals live in couples. The optimization problem defining the optimal gender neutral allocation is formally stated in Appendix A.7.

The objective function and the incentive constraints all account for the fact that couples pool their incomes. The problem differs from its first-best counterpart in that we have added three incentive constraints which ensure gender neutrality. ${ }^{20}$ The first constraint (A.31) with multiplier $\lambda^{c}$ ensures that female and male do not both deviate by choosing the other's spouse retirement age while (A.32) with multiplier $\lambda_{f}^{c}$, is that of the female spouse choosing the retirement age intended for the male's one while (A.33), with multiplier $\lambda_{m}^{c}$, is that of the male spouse choosing the retirement age intended for the female's one.

\subsubsection{Properties of the solution}

We have the following proposition

Proposition 7 (Gender neutrality with couples) (i) The first-best allocation described in Proposition 4 with $P_{f}^{c}\left(\tau_{f}^{c F B}\right)=P_{m}^{c}\left(\tau_{m}^{c F B}\right)=0$ is incentive compatible iff $\tau_{f}^{c F B} \leq \tau_{m}^{c F B}$

(ii) If $\tau_{f}^{c F B}>\tau_{m}^{c F B}$, the second-best allocation entails the incentive compatibility constraint (A.31) to be binding with $\tau_{f}^{c S B}=\tau_{m}^{c S B}$ and $P_{f}^{c}\left(\tau_{f}^{c S B}\right)=P_{m}^{c}\left(\tau_{m}^{c S B}\right)=0$.

Constraint (A.31) is clearly violated when $\tau_{f}^{c F B}>\tau_{m}^{c F B}$, since switching roles yields a higher life-cycle income but the same total labor disutility for the couple. Consequently the first best cannot be implemented in this case and this establishes the "only if" part of statement (i). Furthermore, it implies that in the gender neutral problem we have to impose the constraint $\tau_{f}^{c} \leq \tau_{m}^{c}$ which is obviously binding when $\tau_{f}^{c F B}>\tau_{m}^{c F B}$. This immediately gives us part (ii) of the proposition. For the "if" part of $(i)$, the first

\footnotetext{
${ }^{20}$ And, as explained above, we use $P_{j}$ and $\tau_{j}$ as decision variables rather than $c_{j}$ and $\tau_{j}$ in the first best.
} 
incentive constraint, (A.31), plays no role: it is obviously satisfied in that case. To complete the proof that the first best can be implemented, it thus remains to be shown that the other constraints, namely conditions (A.32) and (A.33) are also satisfied, which we do in Appendix A.8. Intuitively, when the FB implies $\tau_{f}^{c F B} \leq \tau_{m}^{c F B}$, the couples' allocation differs from the laissez-faire solution (as long a $\varphi^{\prime \prime}<0$ ), but the couple prefers this allocation to one where the female spouse would have to retire later at $\tau_{m}^{c}$ or the male spouse would have to retire earlier at $\tau_{f}^{c}$. Not surprisingly the proof shows that this would only bring the couple further away from its preferred (laissez-faire) retirement ages.

We now turn to the issue of redistribution across spouses. Recall that, with singles only, we can assess the direction of redistribution by looking at the signs of $P^{f}$ and $P^{m}$. With couples, redistribution across spouses can only be achieved via the retirement age.

The main conclusion is that, with couples' consumption pooling, gender neutrality is either irrelevant - namely in case $(i)$ —or limits the possibilities to redistribute towards the shorter-lived male partner, which here can only take place via retirement ages. The order of gender retirement ages cannot be reversed under gender neutrality even when it would be otherwise desirable to further redistribute towards the shorter-lived individuals. When the FB calls for such a reversal, the gender neutral solution implies pooling and thus equal retirement ages. These results are summarized in the following proposition:

Proposition 8 (Redistribution under gender neutrality with couples) When $\varphi$ is not too concave so that $\tau_{f}^{c F B} \leq \tau_{m}^{c F B}$, gender neutrality has no impact on the extent of redistribution across spouses. However, when $\varphi$ is sufficiently concave that FB redistribution in favor of men entails a larger retirement age for women, gender neutrality restricts the possibility to redistribute in favor of men. 


\subsubsection{Implementation}

A direct implication of Proposition 7 is that, in case $(i)$, the results obtained for the FB also apply here. Consequently we have

$$
\frac{\partial P_{f}^{c S B}}{\partial \tau_{f}^{c}}=\frac{\partial P_{f}^{c F B}}{\partial \tau_{f}^{c}}>0>\frac{\partial P_{m}^{c S B}}{\partial \tau_{m}^{c}}=\frac{\partial P_{m}^{c F B}}{\partial \tau_{m}^{c}}
$$

as long as $\varphi^{\prime \prime}<0$. Recall that when $\varphi$ is linear the first best is implementable with $\partial P_{f}^{c} / \partial \tau_{f}=\partial P_{m}^{c} / \partial \tau_{m}=0$, and this result also applies here. Turning to case $(i i)$, it also follows directly from equations (A.12) and (A.13) that $\partial P_{f}^{c S B} / \partial \tau_{f}^{c}>0>\partial P_{m}^{c S B} / \partial \tau_{m}^{c}$ continues to hold. To sum up, as long as $\varphi$ is strictly concave there is always an upward distortion on the retirement age of women and a downward distortion on that of men.

\section{Numerical results}

\subsection{General assessment}

The following simulations illustrate our analytical results, provide a more precise description of the pension system and show which of the cases discussed are likely to arise with empirically relevant parameter values both for the FB and for the gender-neutral second best. We also quantify the size of transfers across groups and the impact of gender neutrality on the different segments of the population: male and female singles and spouses.

In addition, we also study the case where singles and couples coexist. ${ }^{21}$ The firstorder condition in this case remain the same as before. Essentially we put together the conditions for singles of both genders and those for couples. The $S W$ function is then given by the sum of (21) and (A.29) weighted by the proportions of singles and couples in society. To derive the gender neutral solution, we impose all the incentive constraints considered before: (23)-(24) and (A.32)-(A.33). Since the policy can be conditioned on individuals' marital status (there is tagging) this won't affect the qualitative results

\footnotetext{
${ }^{21}$ In a society where single and couples coexist, the decision to get married or remain single might become relevant. The empirical literature documents that a bonus or a penalty generated by the tax scheme does not affect the marriage decision substantially, not even when they are rather sizeable; see Leturcq (2012) for an overview of this literature. If the effect of taxation on the marriage decision is small, we expect that the effect of the pension scheme on the marriage decision is even smaller.
} 
obtained within each group. However, the budget constraint is now "global", so that the solution may imply a transfer between singles and couples. We only consider this case numerically, because the direction of these transfers cannot be determined directly from the first-order conditions; for this one needs an explicit solution (or, at least, one has to make strong assumptions on preferences and distributions). ${ }^{22}$

\subsection{Specification of utilities and calibration of the parameters}

To calibrate the model, we proceed as follows. We assume that individuals start their career at age 25 . We set $T_{f}=60, T_{m}=55, w_{m}=45000$. Consequently women and men live respectively until ages 85 and 80 , with a longevity gap of five years.

To calibrate the share of individuals living in couples, we use estimates and projections from the UN Population Division. Worldwide in 2020, $64 \%$ of women of reproductive age (15 to 49 years) were either married or in a cohabiting union; see Ortiz-Ospina and Roser (2020). The percentage is lower for OECD countries. With lifespans starting at the age of 25 the proportion of couples reported by the UN is likely to be underestimated. Consequently, we approximate the share of couples and singles, by $70 \%$ and $30 \%$ respectively. Hence, the budget constraint writes

$$
0.3\left(P_{m}^{s}\left(\tau_{m}^{s}\right)+P_{f}^{s}\left(\tau_{f}^{s}\right)\right)+0.7\left(P_{m}^{c}\left(\tau_{m}^{c}\right)+P_{f}^{c}\left(\tau_{f}^{c}\right)\right)=0 .
$$

The utility is specified as follows:

$$
U=T u(c)-b R(\tau)
$$

where

$$
\begin{aligned}
& u(c)=\alpha+\left(1 /\left(1-\frac{1}{\varepsilon}\right)\right) c^{1-\frac{1}{\varepsilon}} \\
& R(\tau)=\left(1 /\left(1+\frac{1}{\eta}\right)\right) \tau^{\left(1+\frac{1}{\eta}\right)}
\end{aligned}
$$

so that $\varepsilon$ is the constant intertemporal elasticity of consumption, while $\eta$ is the constant Frisch elasticity of labor supply. We used these utility specifications because $\varepsilon$ and

\footnotetext{
${ }^{22}$ This is a problem well known from the literature on tagging in optimal income taxation (see for instance Cremer et al., 2012a).
} 
$\eta$ have been respectively estimated by Murphy and Topel (2006) and Blundell et al. (2016). Following these studies, we thus set $\varepsilon=1.2$ and $\eta=1$. Note that $\alpha$ is different from 0 as utilities are cardinal in our context (differences between utilities matter in the context of different lifespans except in the case where the social objective is utilitarian).

This leaves us with $b$ and $\alpha$ to calibrate. We proceed in two steps. We first calibrate $b$ so that a single man is indifferent between retiring at $\tau_{m}^{s}=40$ and 41 , which requires that $b$ solves the following equation

$$
T_{m} u\left(\frac{40 w_{m}}{T_{m}}\right)-b R(40)=T_{m} u\left(\frac{41 w_{m}}{T_{m}}\right)-b R(41)
$$

in which $\alpha$ cancels out. Solving yields $b=0.19$.

Second, in order to calibrate $\alpha$, we first calculate the optimal retirement age for a single man with a lifespan of $T_{m}$ and a lifetime labor income of $w_{m} \tau_{m}-e$, where $e$ denotes the willingness to pay for an additional year of life at age 25; see below. For such a worker, optimal retirement $\tau_{m}^{*}$ is given by

$$
\tau_{m}^{*}\left(T_{m}, e\right)=\arg \max _{\tau_{m}} T_{m} u\left(\frac{w_{m} \tau_{m}-e}{T_{m}}\right)-b R\left(\tau_{m}\right),
$$

which yields the following indirect utility function

$$
V\left(T_{m}, e\right)=T_{m} u\left(\frac{w_{m} \tau^{*}\left(T_{m}, e\right)-e}{T_{m}}\right)-b R\left(\tau^{*}\left(T_{m}, e\right)\right) .
$$

Now, $e$ represents the willingness to pay for an additional year of life at age 25 if it solves:

$$
V\left(T_{m}, e\right)=V\left(T_{m}+1,0\right) .
$$

We calibrate $e$ to be 200000; see Murphy and Topel (2006). From (27) we obtain

$$
\begin{aligned}
\alpha & =u\left(\frac{w_{m} \tau^{*}\left(T_{m}, e\right)-e}{T_{m}}\right)-u\left(\frac{w_{m} \tau^{*}\left(T_{m}+1,0\right)}{T_{m}+1}\right) \\
& -b R\left(\tau^{*}\left(T_{m}, e\right)\right)+b R\left(\tau^{*}\left(T_{m}+1,0\right)\right) .
\end{aligned}
$$

Using (27) and (28), and then solving, yields $\alpha=-14.13$.

We consider three scenarios concerning the degree of concavity of the $S W$ function specified by (11), ranging from a low degree of concavity to a quite large one. In 
Scenario 1 we set $v=0.5$ which is a relatively low value. It implies that the concern for redistributing in favor of women, who are characterized by a lower yearly income, is relatively stronger. In Scenario 2, the intermediate case, we have $v=2$; social welfare is more concave and implies that the concern for redistributing in favor of the short-lived men becomes relatively stronger. Finally, in Scenario 3 with $v=10$, we consider a quite large degree of concavity.

As mentioned in the Introduction, the gender wage gap amounts to $15 \%$ in Europe (Eurostat 2020). By setting $w_{m}=45000$, this gap translates into a yearly female income of $w_{f}=38000$. The $15 \%$ gap is computed considering the gap in the hourly wage rate of full-time employed workers, and is thus underestimating the yearly gender gap in income, because women have a lower employment rate than men, work part-time more often and, have career interruptions due to childbearing and child care. In other words, it represents a low range of the possible estimates. Our results bear out that even with this low value, the wage gap turns out to be the dominant source of heterogeneity. In particular even with the more concave SW function we continue to have redistribution from single men to single women. This explains that an alternative setting with a wage gap of $20 \%$ yields similar results. ${ }^{23}$

\subsection{Scenario 1: $\nu=0.5$}

Results for the cases of singles and couples in isolation are reported in Table 1. Results when singles and couples coexist are depicted in Table 2.

\subsubsection{Singles}

Let us start from the laissez-faire for singles (Table 1). Women retire later than men but consume less. The first best implies redistribution from men to women. In the first best women receive an implicit transfer and $P_{f}^{s F B}=-P_{m}^{s F B}>0$. Moreover, single women retire earlier and single men retire later than in the laissez-faire. When gender neutrality is imposed, one can check that, as expected, $I C_{m f}$ binds for singles meaning

\footnotetext{
${ }^{23}$ We do not report them to avoid tedious repetitions but they can be obtained from the authors upon request.
} 
that single men are the mimickers. In the second best, women receive a lower implicit transfer than otherwise optimal. Retirement age is not distorted for single men but it is upward distorted for women so that we obtain $\tau_{f}^{s 1 S B}>\tau_{m}^{s 1 S B}$, where the superscript $s 1 S B$ indicates the second-best result of scenario 1 for singles only. ${ }^{24}$ We conclude that, in this scenario, gender neutrality dramatically impairs single women by decreasing the amount of feasible redistribution. Indeed, the second best does not significantly improve welfare compared to the laissez-faire, because the benefit single women obtain from the slightly larger per-period consumption is almost fully offset by the disutility from labor supply generated by the increase in their retirement age. To sum up, in Scenario 1, with singles only, gender neutrality is highly detrimental to women.

\subsubsection{Couples}

In the laissez-faire spouses have the same per-period consumption but women retire earlier than their partners. First best requires redistribution from women to men that can only be achieved through an adjustment of retirement ages: women's retirement age increases while that of men decreases compared to the laissez-faire. However, in the first best we continue to have $\tau_{f}^{c 1 F B}<\tau_{m}^{c 1 F B}$ which implies that the first best is incentive compatible (Part (i) of Proposition 7 applies). In other words, the first-best allocation can be implemented by a gender neutral pension scheme. As a result, in Scenario 1 for couples only, gender neutrality does not limit the extent of redistribution in favor of male spouses that the government wants to achieve. In the second best, female spouses are worse off while male spouses are better off with respect to the laissez-faire. However this is not due to gender neutrality but to the concavity of social welfare which calls for redistribution from female to male spouses.

\subsubsection{Singles and couples}

When singles and couples coexist, both transfers between men and women and transfers between singles and couples are possible. Within this context, both pension benefits for single men and single women are relevant because $P_{f}^{s F B} \neq-P_{m}^{s F B}$. In addition, for

\footnotetext{
${ }^{24}$ Case $(i b)$ of Proposition 9 in Appendix A.6 applies here.
} 


\begin{tabular}{|c|c|c|c|c|c|c|}
\hline & \multicolumn{3}{|c|}{ Singles only } & \multicolumn{3}{c|}{ Couples only } \\
\hline Allocations & $L F$ & $F B$ & $S B$ & $L F$ & $F B$ & $S B$ \\
\hline$c_{f}$ & 26277 & 28654 & 26353 & 29722 & 29624 & 29624 \\
\hline$c_{m}$ & 33135 & 30712 & 33129 & 29722 & 29624 & 29624 \\
\hline$\tau_{f}$ & 41.49 & 38.60 & 41.59 & 37.44 & 38.80 & 38.80 \\
\hline$\tau_{m}$ & 40.49 & 43.14 & 40.50 & 44.33 & 42.93 & 42.93 \\
\hline$P_{f}$ & 0 & 252383 & 613 & 0 & 0 & 0 \\
\hline$P_{m}$ & 0 & -252383 & -613 & 0 & 0 & 0 \\
\hline$P_{f}^{\prime}$ & 0 & 0 & 187 & 0 & 1276 & 1276 \\
\hline$P_{m}^{\prime}$ & 0 & 0 & 0 & 0 & -1540 & -1540 \\
\hline$U_{f}$ & 951 & 1001 & 951 & 1022 & 1011 & 1011 \\
\hline$U_{m}$ & 936 & 892 & 936 & 872 & 882 & 882 \\
\hline
\end{tabular}

Table 1: Scenario 1 with a low degree of concavity of the $S W F$. The table shows the laissez-faire $(L F)$, the first best $(F B)$ and the gender-neutral second best $(S B)$ with singles only and couples only. Gender neutrality is highly detrimental to single women while it does not affect couples because the FB for couple is incentive compatible.

couples the total pension benefit $P^{c}\left(=P_{f}^{c}+P_{m}^{c}\right)$ matters here. Recall that before we had $P^{c}=0$, but when couples and singles coexist the total pension benefit for couples can be positive or negative: $P^{c} \lessgtr 0$. The results are reported in Table 2 . The laissez-faire remains of course the same as in the economy with only singles and only couples; see Table 1.

The first best implies that implicit transfers are paid by single men mainly in favor of single women and to a lesser extent in favor of couples: $P_{f}^{s 1 F B *}=251479$ and $P^{c 1 F B *}=803$ are both positive while $P_{m}^{s 1 F B *}=-253307$ is negative. Here the star in the superscript (i.e. $s 1 F B *$ ) indicates that singles and couples coexist in Scenario 1. However, in the second best, couples receive a negative net pension benefit and are the ones who subsidize pensions of both single women and single men; we have indeed $P^{c 1 S B *}=-14255, P_{f}^{s 1 S B *}=17206$ and $P_{m}^{s 1 S B *}=15265$. This occurs because, under gender neutrality, $I C_{m f}$ binds for single men and this prevents the desirable redistribution from single men to single women and to couples. In addition, no incentive constraint binds in couples; thus the optimal redistribution in the couple can take place, female spouses retire later while male spouses retire earlier than in the laissez-faire. On 
the contrary, the retirement decisions of singles in the second best are similar to the ones in laissez-faire: the retirement age of single women is slightly distorted upwards, while the retirement age of single men is not distorted but slightly decreases with respect to the laissez-faire because of the implicit transfer single men receive in the second best.

Finally, let us consider redistribution for men and women overall. To check how gender neutrality affects overall redistribution, we have to compare net benefits $P_{f}+P_{c} / 2$ received by all women in the first-best and second-best allocation (we assume here that the level of the pension benefit of a couple is shared equally between spouses). From Table 2, and recalling that the share of singles in each gender is 0.3 we obtain that in the first-best solution, singles and married women receive average net benefits equal to $0.3 P_{f}+0.7 P_{c} / 2=0.3 \times 251479+0.7 \times 401.5=75724.75$. This measures overall redistribution from men to women in per capita terms. Note that here men living in couple are net recipient of the pension scheme and only single men are net contributors to the pension scheme. The amount 7572.75 indicates overall average redistribution from men to women. This roughly represents 3 years of consumption for single women. In the second best, $0.3 P_{f}+0.7 P_{c} / 2=17206+(-7127.5)=172.55$ which now only corresponds to $0.6 \%$ of yearly consumption for a single woman. Notably, here only single women receive a positive net benefit, while married women are contributing to such redistribution towards single women. In different words, married individuals are net contributors. Hence, gender neutrality is detrimental to all women, and women in couples move from net recipients to net contributors.

To conclude, in Scenario 1, in a mixed economy gender neutrality impairs both single women and, to a lower extent, male spouses: it fully prevents optimal redistribution from single men to couples and limits redistribution in favor of single women substantially. In general, there is a net redistribution from men to women overall, both in the first best and the second best, but this redistribution only favors single women.

\subsection{Scenario 2: $\nu=2$}

We now consider a more concave social welfare function which reflects a larger concern for redistribution in favor of short-lived men. Obviously, this does not affect the laissez- 


\begin{tabular}{|c|c|c|c|}
\hline \multirow{4}{*}{ Singles } & Allocations & First Best & Second best \\
\cline { 2 - 4 } & $c_{f}$ & 28645 & 26502 \\
\cline { 2 - 4 } & $c_{m}$ & 30703 & 33295 \\
\cline { 2 - 4 } & $\tau_{f}$ & 38.61 & 41.39 \\
\cline { 2 - 4 } & $\tau_{m}$ & 43.15 & 40.33 \\
\cline { 2 - 4 } & $P_{f}$ & 251479 & 17206 \\
\cline { 2 - 4 } & $P_{m}$ & -253353 & 16055 \\
\cline { 2 - 4 } & $P_{f}^{\prime}$ & 0 & 181 \\
\cline { 2 - 4 } & $P_{m}^{\prime}$ & 0 & 0 \\
\cline { 2 - 4 } & $U_{f}$ & 1001 & 954 \\
\hline & $U_{m}$ & 892 & 939 \\
\cline { 2 - 4 } & $c$ & 29628 & 29557 \\
\cline { 2 - 4 } & $\tau_{f}$ & 38.80 & 38.88 \\
\cline { 2 - 4 } & $\tau_{m}$ & 42.93 & 43.01 \\
\cline { 2 - 4 } & $=P_{f}+P_{m}$ & 803 & -14255 \\
\cline { 2 - 4 } & $P_{f}^{\prime}$ & 1275 & 1277 \\
\cline { 2 - 4 } & $P_{m}^{\prime}$ & -1539 & -1542 \\
\cline { 2 - 4 } & $U_{f}$ & 1011 & 1009 \\
\cline { 2 - 4 } & $U^{c}$ & 882 & 881 \\
\hline
\end{tabular}

Table 2: Scenario 1 with a low concavity of the $S W F$. The Table shows results when singles and couples coexist. Gender neutrality impairs both single women and, to a lower extent, male spouses, while it greatly benefits single men. Redistributing from single men to couples become impossible. 
faire which remains the same as in Scenario 1. Tables 3 and 4 contain results for this scenario.

\subsubsection{Singles}

Given that the concern for heterogeneity in lifespan is stronger, in the first-best allocation single men are better off while single women are worse off with respect to Scenario 1. From Table 3, specifically, single women should receive a lower net pension benefit $\left(P_{f}^{s 2 F B}=122075\left(=-P_{m}^{s 2 F B}\right)<P_{f}^{s 1 F B}=252383\right)$, enjoy a lower per-period consumption and retire later than in Scenario 1. The opposite holds for single men. Nevertheless, redistribution from men to women continues to be desirable and this explains why, adding gender neutrality, single men are the mimicker and $I C_{m f}$ continues to bind. As a result, in Scenario 2 for singles only, gender neutrality limits the extend of feasible redistribution across singles individuals substantially and, in the second best, women receive an extremely low and suboptimal net pension benefit.

\subsubsection{Couples}

As expected, we observe that the desired level of redistribution from women to their spouses is larger than in Scenario 1. Now, the optimal increase in female retirement age and the decrease in male retirement age are much more pronounced than before and $\tau_{f}^{c 2 F B}>\tau_{m}^{c 2 F B}$ holds. Part ( $\left.i i\right)$ of Proposition 7 applies because the "no switching" incentive constraint binds for couples here. Hence, gender neutrality requires that both spouses retire at the same age $\left(\tau_{f}^{c 2 S B}=\tau_{m}^{c 2 S B}\right)$ and thus makes female spouses better off with respect to the FB. To conclude, in Scenario 2 for couples only, gender neutrality limits the extent of redistribution in favor of male spouses.

\subsubsection{Singles and couples}

From Table 4, the FB with singles and couples is similar to its counterpart in Scenario 1 , except that the desired redistribution in favor of single women is lower, while the desired redistribution in favor of male spouses is higher than in Scenario 1, because here the concern for the short-lived man is stronger. As a result, in the second best, male 


\begin{tabular}{|c|c|c|c|c|c|c|}
\hline & \multicolumn{3}{|c|}{ Singles } & \multicolumn{3}{c|}{ Couples } \\
\hline Allocations & $L F$ & $F B$ & $S B$ & $L F$ & $F B$ & $S B$ \\
\hline$c_{f}$ & 26277 & 27406 & 26344 & 29722 & 29542 & 29536 \\
\hline$c_{m}$ & 33135 & 31943 & 33129 & 29722 & 29542 & 29536 \\
\hline$\tau_{f}$ & 41.49 & 40.06 & 41.58 & 37.44 & 41.38 & 40.92 \\
\hline$\tau_{m}$ & 40.49 & 41.75 & 40.50 & 44.33 & 40.54 & 40.92 \\
\hline$P_{f}$ & 0 & 122075 & 598 & 0 & 0 & 0 \\
\hline$P_{m}$ & 0 & -122075 & -598 & 0 & 0 & 0 \\
\hline$P_{f}^{\prime}$ & 0 & 0 & 164 & 0 & 3793 & 3317 \\
\hline$P_{m}^{\prime}$ & 0 & 0 & 0 & 0 & -4054 & -3682 \\
\hline$U_{f}$ & 951 & 975 & 951 & 1022 & 990 & 994 \\
\hline$U_{m}$ & 936 & 915 & 936 & 872 & 900 & 898 \\
\hline
\end{tabular}

Table 3: Scenario 2 with a larger degree of concavity of the $S W F$. The table shows the laissez-faire ( $L F)$, the first best $(F B)$ and the gender-neutral second best (SB) with singles only and couples only. Gender neutrality remains detrimental to single women, but to a lower extent than in Scenario 1. The FB for couple is no more incentive compatible and retirement ages are equalized. Hence, gender neutrality is also detrimental to male spouses.

spouses are better off in the second scenario than in the first one, while the opposite holds for single women. In the second-best setting, not much changes for singles with respect to the first scenario: single women continue to retire later than men, and the difference between retirement ages is the same in the two scenarios. However, in the second scenario, both single men and women receive a lower transfer from couples than in the first scenario. The incentive constraint of single men continues to be binding.

In the first best, couples's net pension benefit is positive and amounts to $P_{f}^{c 2 F B *}=$ 2586 but, in the second best, it decreases dramatically and becomes negative, $P_{f}^{c 2 S B *}=$ -4608. Like in the first scenario couples should be net recipients in the first best but they are net contributors in the second best. The only significant difference between the two scenarios is that the desired retirement age for female spouses in now larger than that for male spouses in the first best $\left(\tau_{f}^{c 2 F B *}>\tau_{m}^{2 c F B *}\right)$. Consequently, we obtain the pooling regime described in Proposition 7 (ii) with $\tau_{f}^{c 2 S B *}=\tau_{m}^{2 c S B *}$.

Finally, overall redistribution from men to women is on average equal to 36663,6 in the first best. This roughly corresponds to 1.5 years of consumption for single wo- 
men. In the second best, single and married women receive on average 175,8 , which represents a tiny part of one year of annual consumption for single women. Again, imposing gender neutrality reduces redistribution towards single women and all married individuals. Specifically, because of gender neutrality, married individuals (women included) move from net recipients to net contributors.

The qualitative conclusions of the first scenario continue to apply, but effects are here mitigated by the more concave SW function. In Scenario 2, in the mixed economy gender neutrality impairs single women and male spouses. It benefits single men. It partially prevents redistribution in favor of single women, and reverses the direction of the transfer between couples and singles resulting in negative net benefits for couples. Overall, there is a net redistribution from men to women, both in the first best and the second best, but this redistribution only favour single women and is lower than in the preceding scenario.

\subsection{Scenario 3: $\nu=10$}

As a robustness check, we consider a very high value of the degree of concavity of the social welfare function. This reflects an even larger concern for redistribution in favor of short-lived men (the tables are relegated to Appendix A.9). The results are qualitatively the same as with $v=2$. The only change is related to the redistribution from singles to couples and from men to women overall. In the first best, average redistribution from men to women is reduced to the very small value of 3010 (see Table 5 in Appendix A.9) and, as with the two other scenarios, single women and couples are net recipients. However, the second best implies an overall redistribution from men to women equal to 95 (see Table 6). There, single men and women are net contributors to the pension scheme while couples are net recipient. This is due to the fact that there is a very strong concern for redistribution towards men. Since the second best requires the same retirement age for the two spouses in couples, redistribution towards male spouses becomes more important. This can only be done via a transfer from singles to couples.

In Scenario 3, in the mixed economy gender neutrality impairs single women and male spouses. The direction of the transfer between couples and singles results in positive 


\begin{tabular}{|c|c|c|c|}
\hline & Allocations & First Best & Second Best \\
\hline Singles & $c_{f}$ & 27379 & 26392 \\
\cline { 2 - 4 } & $c_{m}$ & 31913 & 33183 \\
\cline { 2 - 4 } & $\tau_{f}$ & 40.09 & 41.51 \\
\cline { 2 - 4 } & $\tau_{m}$ & 41.78 & 40.45 \\
\cline { 2 - 4 } & $P_{f}$ & 119195 & 5962 \\
\cline { 2 - 4 } & $P_{m}$ & -125230 & 4791 \\
\cline { 2 - 4 } & $P_{f}^{\prime}$ & 0 & 161 \\
\cline { 2 - 4 } & $P_{m}^{\prime}$ & 0 & 0 \\
\cline { 2 - 4 } & $U_{f}$ & 975 & 952 \\
\cline { 2 - 4 } & $U_{m}$ & 915 & 937 \\
\hline Couples & $c$ & 29555 & 29514 \\
\cline { 2 - 4 } & $\tau_{f}$ & 41.37 & 40.94 \\
\cline { 2 - 4 } & $\tau_{m}$ & 40.53 & 40.94 \\
\cline { 2 - 4 } & $P^{c}=P_{f}+P_{m}$ & 2586 & -4608 \\
\cline { 2 - 4 } & $P_{f}^{\prime}$ & 3793 & 3317 \\
\cline { 2 - 4 } & $P_{m}^{\prime}$ & -4054 & -3682 \\
\cline { 2 - 4 } & $U_{f}$ & 990 & 993 \\
\cline { 2 - 4 } & $U_{m}$ & 901 & 897 \\
\hline
\end{tabular}

Table 4: Scenario 2 with a larger degree of concavity of the $S W F$. The Table shows results when singles and couples coexist. Gender neutrality continues to impair both single women and male spouses, while it benefits single men. Retirement ages are equalized in the couple. Redistributing from single men to couples is still impossible but male spouses are better off with respect to Scenario 1. 
net benefits for couples and negative ones for singles. Overall, there is a net redistribution from women to men, but this redistribution only favors married individuals.

\section{Concluding comments}

This paper has studied the design of pension schemes for male and female workers. Pension benefits net of contributions depend on the retirement age, which individuals choose given the benefit rule. Women live longer than men but have a lower wage. Individuals can be single or live in couples. Couples pool their incomes and equalize spouses' per-period consumption. Social welfare is utilitarian but the sum is taken over an increasing concave transformation of individuals' lifetime utilities in order to introduce the concern for redistribution between individuals with different lifespans.

The following main lessons have emerged. First, the social planner's concern for redistribution between individuals with different lifespans plays a crucial role in determining the desired direction of redistribution across genders and, thus, male and female optimal retirement ages. Second, resource pooling by couples limits the possibilities of gender redistribution via the level of net pension benefits. Instead, retirement ages, as determined by the specific design of the benefit rules now play an even more crucial role. Third, gender neutrality, though appealing on grounds of horizontal equity comes at a welfare cost. It limits the possibilities to redistribute across genders and may imply distortions of retirement ages. Depending on the specific case, they may be lower or higher than otherwise optimal.

Elaborating on the third point, we have shown that because gender neutrality limits redistribution it negatively affects the group towards which redistribution is targeted. In turn, the gender and the marital status of the beneficiaries of redistribution depend on the concavity of the social welfare function. When the theoretical result is ambiguous, we used our calibrated numerical examples to obtain empirically relevant predictions. The impact of gender neutrality is most notable when there are singles only. In this case singles women are the target of redistribution and we conclude that gender neutrality limits such redistribution substantially. 
Conversely, with a strictly concave social welfare function and a society only populated by couples, male spouses are always the target of redistribution and may therefore be adversely affected by gender neutrality. When the first-best level of redistribution towards male spouses is small, it can also be implemented under gender neutrality via an appropriate adjustment of retirement ages. Here gender neutrality has no cost. When instead the desired level of redistribution is so large that female workers would have to retire later than their spouses, it cannot be implemented under gender neutrality. The constrained pension scheme then involves pooling of retirement ages and redistribution is limited by gender neutrality.

Finally, we have shown though our simulations that, in a setting with singles and couples, gender neutrality impairs both single women and male spouses: it dramatically limits redistribution in favor of single women and reverses the direction of the transfer between couples and singles resulting in negative net benefits for couples. Overall female spouses are not much affected by gender neutrality because it has two opposite effects. On the one hand, it limits redistribution from women to men inside the couple, thus making female spouses better off. On the other hand, it prevents redistribution in favor of couples thus making female spouses worse off. To conclude, gender neutrality is greatly advantageous to single men who should be the "net contributors" in this setting with singles and couples, but end up being "net beneficiaries".

Gender neutrality adds an extra constraint for the design of pension systems. In a purely normative model such a constraint can only reduce overall welfare. However, in reality "horizontal equity" requirements are often imposed as a safeguard against arbitrary discrimination, particularly when policy decisions are determined by some political process. From that perspective the advocates of gender neutrality may well be inspired by the motivation to prevent arbitrary gender discrimination. For instance the EU might want to impose gender neutrality when it thinks that the political process in some member States might be biased against women. But in a setting where all decision are made according to the same welfare function, our analysis has shown to what extent gender neutrality is detrimental to single women. Second, it has shown that married men should be the target of redistribution as well. As a result, gender 
neutrality negatively affects single women and also married men.

Redistribution across genders is motivated by both the longevity gap and the wage gap. The two gaps may be decreasing but, as long as they continue to exist, some redistribution across genders is welfare improving and gender neutrality brings about the negative consequences for men and women that our results have highlighted. Hence, until some redistribution across genders is desirable, the call for gender neutrality appears to be premature. As we mentioned in the Introduction some derogations to gender neutrality have been allowed to compensate for women's disadvantages in their professional life and for the time they devoted to childcare. Such derogations mitigate the problem for single and divorced women but they may not be sufficient and represent just a patch for some of the issues. In addition, no derogations have been suggested for married men who, like single women, are negatively affected by gender neutrality.

This paper presents just a "first pass" at studying the overall issue. It needs to be completed in different directions. In particular, we have neglected complementarities in leisure between spouses which in reality are likely to affect couples' retirement decisions. Furthermore, we have assumed that all persons of a given gender have the same wage. In reality, however, pension schemes often redistribute also across income groups of the same gender. When wage heterogeneity is introduced gender and income redistribution become intertwined problems and gender neutrality can be expected to have an even more drastic impact. All these issue are on our research agenda.

\section{References}

[1] Atkinson, A., and F. Bourguignon (1982), "The comparison of multidimensional distribution of economic status," Review of Economic Studies 49, 183-201.

[2] Bertrand M. (2020), "Gender in the 21st Century," American Economic Association Papers and Proceedings 110(5), 1-24.

[3] Blau, F.D., and L.M. Kahn (2017), "The gender wage gap: extent, trends, and explanations," Journal of Economic Literature 55(3), 789-865. 
[4] Blundell, R., E. French and G.Tetlow (2016), "Retirement Incentives and Labor Supply," Handbook of the Economics of Population Aging, Volume 1, 457566.

[5] Bommier, A. (2006), "Uncertain lifetime and intertemporal choice: risk aversion as a rationale for time discounting," International Economic Review 47, 1223-46.

[6] Bommier, A, M.L. Leroux and J.M. Lozachmeur (2011a), "Differential mortality and social security," Canadian Journal of Economics 44, 273-289.

[7] Bommier A., M.L. Leroux and J.M. Lozachmeur (2011b), "On the Public Economics of Annuities with Differential Mortality", Journal of Public Economics $95,612-623$.

[8] Becker, G.S., T.J. Philipson, and R.R Soares (2005), "The quantity and quality of life and the evolution of world inequality," American Economic Review 95, 277-91.

[9] Bohàcek R., J. Bueren, L. Crespo, P. Mira and J. Pijoan-Mas (2021), "Inequality in life expectancies across Europe and the US," Health Economics, 30 ( 8), $1871-1885$.

[10] Britton, J. and French, E. (2020), "Health and Employment amongst Older Workers," Fiscal Studies, 41: 221-250.

[11] Cremer H., F. Gahvari and J.M. Lozachmeur (2012a), "Tagging and income taxation: theory and an application," American Economic Journal: Economic Policy 2, 31-50.

[12] Cremer H., J.M. Lozachmeur and P. Pestieau (2004), "Social security, retirement age and optimal income taxation," Journal of Public Economics 88, 22592281.

[13] Cremer H., J.M. Lozachmeur and P. Pestieau (2012b), "Income taxation of couples and the tax unit choice," Journal of Population Economics 25 (2), 763-778. 
[14] Cullen, M.R., M. Baiocchi, K. Eggleston, P. Loftus, V. Fuchs (2016), "The weaker sex? Vulnerable men and women's resilience to socio-economic disadvantage," SSM - Population Health 2, 512-524.

[15] European Institute for Gender Equality (2019), Gender Equality Index 2019. Retrieved from: //eige.europa.eu/publications/gender-equality-index-2019-report.

[16] European Parliament, Policy Department for Economic, Scientific and Quality of Life Policies Directorate-General for Internal Policies (2019), "The gender gap in pensions in the EU", retrieved from: www.europarl.europa.eu/supporting-analyses.

[17] Fleurbaey, M., M-L. Leroux, P. Pestieau, and G. Ponthiere G (2016), "Fair retirement under risky lifetime", International Economic Review, 57(1), 177-209.

[18] Finkelstein, A., J. Poterba and C. Rothschild (2009), "Redistribution by insurance market regulation: Analyzing a ban on gender-based retirement annuities," Journal of Financial Economics 91, 38-58.

[19] Goldin C., A. Lleras-Muney (2019), "XX>XY?: The Changing Female Advantage in Life Expectancy," Journal of Health Economics 67, 102224.

[20] Gottschalk, P., and E. Spolaore (2002), "On the evaluation of economic mobility," Review of Economic Studies 69, 191-208.

[21] Leroux, M. L. and G. Ponthiere (2013), "Utilitarianism and unequal longevities: A remedy?" Economic Modelling, 30, 888-899.

[22] Leturcq, M., (2012), "Will you civil union me? taxation and civil unions in France," Journal of Public Economics, 96, 541-552

[23] Murphy, K.M. and R.H. Topel (2006), "The Value Of Health And Longevity," Journal of Political Economy 114 (5), 871-904.

[24] Ndiaye, A. (2020), "Flexible Retirement and Optimal Taxation", mimeo. 
[25] OECD (2021), Towards Improved Retirement Savings Outcomes for Women, OECD Publishing, Paris, https://doi.org/10.1787/f7b48808-en.

[26] Ortiz-Ospina E. and M. Roser (2020), "Marriages and Divorces". Published online at OurWorldInData.org. Retrieved from: https://ourworldindata.org/marriages-and-divorces.

[27] Pestieau, P. and M. Racionero (2016), "Harsh occupations, life expectancy and social security," Economic Modelling 58, 194-202.

[28] Sheshinski, E., FN. Caliendo (2021), "Social Security and the increasing longevity gap." Journal of Public Economic Theory 23, 29-52.

[29] UK Parliament (2022), "The Gender Pension Gap," available at https://researchbriefings.files.parliament.uk/documents/CBP-9517/CBP-9517.pdf

[30] World Economic Forum (2021), "How to fix the gender pension gap," https://www.weforum.org/agenda/2021/09/how-to-fix-the-gender-pension-gap/.

\section{A Appendix}

\section{A.1 First-best allocation, singles only: first-order conditions}

$$
\begin{aligned}
& \frac{\partial \mathcal{L}}{\partial c_{f}}=\varphi^{\prime}\left(U_{f}^{s}\right) T_{f} u^{\prime}\left(c_{f}^{s}\right)-\mu T_{f}=0, \\
& \frac{\partial \mathcal{L}}{\partial c_{m}}=\varphi^{\prime}\left(U_{m}^{s}\right) T_{m} u^{\prime}\left(c_{m}^{s}\right)-\mu T_{m}=0, \\
& \frac{\partial \mathcal{L}}{\partial \tau_{f}}=-\varphi^{\prime}\left(U_{f}^{s}\right) R^{\prime}\left(\tau_{f}^{s}\right)+\mu w_{f}=0, \\
& \frac{\partial \mathcal{L}}{\partial \tau_{m}}=-\varphi^{\prime}\left(U_{m}^{s}\right) R^{\prime}\left(\tau_{m}^{s}\right)+\mu w_{m}=0 .
\end{aligned}
$$

\section{A.2 Proof of Proposition 2}

The proof is by contradiction. Assume $U_{f}^{s F B}<U_{m}^{s F B}$ so that $\varphi^{\prime}\left(U_{f}^{s F B}\right)>\varphi^{\prime}\left(U_{m}^{s F B}\right)$ which, using (14), implies $c_{f}^{s F B}>c_{m}^{s F B}$. Using (13), together with $w_{f} \leq w_{m}$, this implies that $\tau_{f}^{s F B}<\tau_{m}^{s F B}$. But $c_{f}^{s F B}>c_{m}^{s F B}$ and $\tau_{f}^{s F B}<\tau_{m}^{s F B}$ implies $U_{f}^{s F B}>U_{m}^{s F B}$. 
A contradiction. The first best solution thus involves $U_{f}^{s F B} \geq U_{m}^{s F B}$ which by (14) implies $c_{m}^{s F B} \geq c_{f}^{s F B}$.

Point $(i)$. When $\varphi$ is linear, (14) implies $c_{f}^{s F B}=c_{m}^{s F B}$, so that by (13) it yields $\tau_{f}^{s F B}<\tau_{m}^{s F B}$.

Now when $\varphi$ is Rawlsian, individual utilities are equalized i.e.:

$$
U_{f}^{s F B}=T_{f} u\left(c_{f}^{s F B}\right)-R\left(\tau_{f}^{s F B}\right)=U_{m}^{s F B}=T_{m} u\left(c_{m}^{s F B}\right)-R\left(\tau_{m}^{s F B}\right) .
$$

Point (ii). Assume that $\tau_{f}^{s F B} \leq \tau_{m}^{s F B}$ and $\varphi$ is Rawlsian, then if $w_{f}=w_{m}$, (13) yields $c_{m}^{s F B} \leq c_{f}^{s F B}$ and thus $U_{f}^{s F B}>U_{m}^{s F B}$. This contradicts (A.1).

Point (iii). Assume $\tau_{m}^{s F B} \leq \tau_{f}^{F B}$ and $\varphi$ is Rawlsian, then if $T_{f}=T_{m}=T$, (13) yields $c_{m}^{s F B}>c_{f}^{s F B}$. Since $(A .1)$ implies $R\left(\tau_{f}^{s F B}\right)-R\left(\tau_{m}^{s F B}\right)=T\left[u\left(c_{f}^{s F B}\right)-u\left(c_{m}^{s F B}\right)\right] \geq 0$ i.e. $c_{m}^{s F B} \leq c_{f}^{s F B}$ so that we have a contradiction.

\section{A.3 First-order conditions of problem (16)}

Denoting the multiplier associated with the resource constraint by $\mu$ we have the following FOCs

$$
\begin{aligned}
& \frac{\partial \mathcal{L}}{\partial c^{c}}=\varphi^{\prime}\left(U_{f}^{c}\right) T_{f} u^{\prime}\left(c^{c}\right)+\varphi^{\prime}\left(U_{m}^{c}\right) T_{m} u^{\prime}\left(c^{c}\right)-\mu\left(T_{f}+T_{m}\right)=0, \\
& \frac{\partial \mathcal{L}}{\partial \tau_{f}}=-\varphi^{\prime}\left(U_{f}^{c}\right) R^{\prime}\left(\tau_{f}^{c}\right)+\mu w_{f}=0, \\
& \frac{\partial \mathcal{L}}{\partial \tau_{m}}=-\varphi^{\prime}\left(U_{m}^{c}\right) R^{\prime}\left(\tau_{m}^{c}\right)+\mu w_{m}=0 .
\end{aligned}
$$

\section{A.4 Proof of Proposition 4}

Combining (A.2) and (A.3) yields

$$
\frac{R^{\prime}\left(\tau_{f}^{c S B}\right)}{u^{\prime}\left(c^{c S B}\right)}=\frac{w_{f}}{\varphi^{\prime}\left(U_{f}^{c S B}\right)}\left[\frac{T_{f} \varphi^{\prime}\left(U_{f}^{c S B}\right)+T_{m} \varphi^{\prime}\left(U_{m}^{c S B}\right)}{T_{f}+T_{m}}\right],
$$

while (A.2) and (A.4) imply

$$
\frac{R^{\prime}\left(\tau_{m}^{c S B}\right)}{u^{\prime}\left(c^{c S B}\right)}=\frac{w_{m}}{\varphi^{\prime}\left(U_{m}^{c S B}\right)}\left[\frac{T_{f} \varphi^{\prime}\left(U_{f}^{c S B}\right)+T_{m} \varphi^{\prime}\left(U_{m}^{c S B}\right)}{T_{f}+T_{m}}\right],
$$

so that

$$
\frac{R^{\prime}\left(\tau_{f}^{c S B}\right) \varphi^{\prime}\left(U_{f}^{c S B}\right)}{w_{f}}=\frac{R^{\prime}\left(\tau_{m}^{c S B}\right) \varphi^{\prime}\left(U_{m}^{c S B}\right)}{w_{m}} .
$$


Using this expression we can now show that we always have $U_{f} \geq U_{m}$, irrespective of the degree of concavity of $\varphi$. The proof is by contradiction. Assume

$$
U_{f}<U_{m} \Longleftrightarrow \varphi^{\prime}\left(U_{f}\right)>\varphi^{\prime}\left(U_{m}\right) .
$$

Since $T_{f} \geq T_{m}$ and $c_{m}=c_{f}=c, U_{f}<U_{m}$ implies

$$
\tau_{f} \geq \tau_{m}
$$

But $w_{f} \leq w_{m}$ yiels $\varphi^{\prime}\left(U_{f}\right)>\varphi^{\prime}\left(U_{m}\right)$ which implies

$$
\frac{w_{f}}{\varphi^{\prime}\left(U_{f}\right)}<\frac{w_{m}}{\varphi^{\prime}\left(U_{m}\right)}
$$

From (A.7), the previous inequality implies $R^{\prime}\left(\tau_{f}\right)<R^{\prime}\left(\tau_{m}\right)$ and thus $\tau_{f}<\tau_{m}$, which contradicts $(A .9)$.

\section{A.5 Proof of equation (18)}

A couple maximizes

$$
\left(T_{f}+T_{m}\right) u\left(c^{c}\right)-R\left(\tau_{f}^{c}\right)-R\left(\tau_{m}^{c}\right)
$$

subject to

$$
w_{f} \tau_{f}^{c}+w_{m} \tau_{m}^{c}+P_{f}^{c}\left(\tau_{f}^{c}\right)+P_{m}^{c}\left(\tau_{m}^{c}\right)-\left(T_{f}+T_{m}\right) c^{c}=0
$$

where $P_{f}^{c}\left(\tau_{f}\right)+P_{m}^{c}\left(\tau_{m}\right)=0$ because we have identical couples. Omitting superscript $c$ to alleviate notation, the FOCs yield:

$$
\begin{gathered}
\frac{R^{\prime}\left(\tau_{f}\right)}{u^{\prime}(c)}=w_{f}+\frac{\partial P_{f}^{c F B}\left(\tau_{f}\right)}{\partial \tau_{f}}, \\
\frac{R^{\prime}\left(\tau_{m}\right)}{u^{\prime}(c)}=w_{m}+\frac{\partial P_{m}^{c F B}\left(\tau_{m}\right)}{\partial \tau_{m}},
\end{gathered}
$$

which are the counterparts to expression (15) in the case of singles. Using the FOCs (A.5) and (A.6) and after some rearrangements, we obtain that the implementing benefit function must satisfy

$$
\frac{\partial P_{f}^{c F B}\left(\tau_{f}\right)}{\partial \tau_{f}}=w_{f}\left[\frac{T_{m}\left(\varphi^{\prime}\left(U_{m}^{c F B}\right)-\varphi^{\prime}\left(U_{f}^{c F B}\right)\right)}{\varphi^{\prime}\left(U_{f}^{c F B}\right)\left(T_{f}+T_{m}\right)}\right]
$$


for $\tau_{f}^{c F B}$. Proceeding in the same way, we obtain

$$
\frac{\partial P_{m}^{c F B}\left(\tau_{m}\right)}{\partial \tau_{m}}=w_{m}\left[\frac{T_{f}\left(\varphi^{\prime}\left(U_{f}^{c F B}\right)-\varphi^{\prime}\left(U_{m}^{c F B}\right)\right)}{\varphi^{\prime}\left(U_{m}^{c F B}\right)\left(T_{f}+T_{m}\right)}\right]
$$

for $\tau_{m}^{c F B}$.

When $\varphi$ is linear, from (A.12) and (A.13) we have

$$
\frac{\partial P_{f}^{c F B}}{\partial \tau_{f}}=\frac{\partial P_{m}^{c F B}}{\partial \tau_{m}}=0
$$

As mentioned above the couples' income pooling imposes no extra constraint here, quite the opposite, it ensures that the laissez-faire corresponds to the FB. In the general case, when $\varphi^{\prime \prime}<0$ together with Proposition 4, equations (A.12)-(A.13) imply equation (18)

\section{A.6 Gender neutrality with singles: statement and proof of formal results}

We concentrate on the case where a single incentive constraint binds. Let us call $\lambda_{f}^{s}$ and $\lambda_{m}^{s}$ the Lagrange multipliers respectively associated with the female and the male IC in the government' problem (see below). The formal results are reported in the following proposition.

Proposition 9 (Gender neutrality with singles) (i) Redistribution from single men to single women: if $\lambda_{m}^{s}>0$ and $\lambda_{f}^{s}=0$ then $M R S_{m}^{s S B}=0$ so that $P^{\prime}\left(\tau_{m}^{s S B}\right)=0$ and we have either (ia) or (ib):

$$
\begin{aligned}
& \text { (ia) } 0>M R S_{f}^{s S B}>M R S_{m f}^{s S B} \\
& \Leftrightarrow P^{\prime}\left(\tau_{f}^{s S B}\right)<0, c_{f}^{s S B}<c_{m f}^{s}<c_{m}^{s S B}, \tau_{f}^{s S B}<\tau_{m}^{s S B} \text { and } U_{m}^{s S B}>U_{f}^{s S B} ; \\
& \text { (ib) } M R S_{m f}^{s S B}>M R S_{f}^{s S B}>0 \Leftrightarrow P^{\prime}\left(\tau_{f}^{s S B}\right)>0, c_{m f}^{s S}>c_{m}^{s S B} \text { and } \tau_{f}^{s S B}>\tau_{m}^{s S B} .
\end{aligned}
$$

(ii) Redistribution from single women to single men: If $\lambda_{f}^{s}>0$ and $\lambda_{m}^{s}=0$, then $M R S_{f}^{s S B}=0$ so that $P^{\prime}\left(\tau_{f}^{s S B}\right)=0$ and we have either (iia) or (iib):

$$
\begin{aligned}
& (i i a) 0>M R S_{m}^{s S B}>M R S_{f m}^{s S B} \Leftrightarrow P^{\prime}\left(\tau_{m}^{s S B}\right)<0, c_{f}^{s S B}>c_{f m}^{s S B} \text { and } \tau_{f}^{s S B}>\tau_{m}^{s S B} \\
& (i i b) M R S_{f m}^{s S B}>M R S_{m}^{s S B}>0 \\
& \Leftrightarrow P^{\prime}\left(\tau_{m}^{s S B}\right)>0, c_{f}^{s S B}<c_{f m}^{s}<c_{m}^{s S B} \Leftrightarrow \tau_{f}^{s S B}<\tau_{m}^{s S B} \Leftrightarrow U_{f}^{s S B}>U_{m}^{s S B} .
\end{aligned}
$$


where $M R S_{m f}^{s}=R^{\prime}\left(\tau_{f}^{s}\right) / u^{\prime}\left(c_{m f}^{s}\right)-w_{m}$ and $M R S_{f m}^{s}=R^{\prime}\left(\tau_{m}^{s}\right) / u^{\prime}\left(c_{f m}^{s}\right)-w_{f}$ with $c_{f m}^{s}=\left(w_{f} \tau_{m}^{s}-P_{f}^{s}\right) / T_{f}$ and $c_{m f}^{s}=\left(w_{m} \tau_{f}^{s}+P_{f}^{s}\right) / T_{m}$.

To establish this proposition we use the resource constraint (22), which implies $P_{m}^{s}=-P_{f}^{s}$ so that the problem of the government can be rewritten as:

$$
\begin{aligned}
\max _{P_{f}^{s}, \tau_{f}^{s}, \tau_{m}^{s}} & \varphi\left[T_{f} u\left(\frac{w_{f} \tau_{f}^{s}+P_{f}^{s}}{T_{f}}\right)-R\left(\tau_{f}^{s}\right)\right]+\varphi\left[T_{m} u\left(\frac{w_{m} \tau_{m}^{s}-P_{f}^{s}}{T_{m}}\right)-R\left(\tau_{m}^{s}\right)\right], \\
& T_{f} u\left(\frac{w_{f} \tau_{f}^{s}+P_{f}^{s}}{T_{f}}\right)-R\left(\tau_{f}^{s}\right) \geq T_{f} u\left(\frac{w_{f} \tau_{m}^{s}-P_{f}^{s}}{T_{f}}\right)-R\left(\tau_{m}^{s}\right), \\
& T_{m} u\left(\frac{w_{m} \tau_{m}^{s}-P_{f}^{s}}{T_{m}}\right)-R\left(\tau_{m}^{s}\right) \geq T_{m} u\left(\frac{w_{m} \tau_{f}^{s}+P_{f}^{s}}{T_{m}}\right)-R\left(\tau_{f}^{s}\right) .
\end{aligned}
$$

where $\lambda_{f}^{s}$ and $\lambda_{m}^{s}$ are the Lagrange multipliers respectively associated with A.15 and A.16. The FOCs with respect to $P_{f}^{s}, \tau_{f}^{s}$ and $\tau_{m}^{s}$ write:

$$
\begin{aligned}
& \quad u^{\prime}\left(c_{f}^{s}\right) \varphi^{\prime}\left[U_{f}^{s}\right]-u^{\prime}\left(c_{m}^{s}\right) \varphi^{\prime}\left[U_{m}^{s}\right] \\
& +\lambda_{f}^{s}\left[u^{\prime}\left(c_{f}^{s}\right)+u^{\prime}\left(c_{f m}^{s}\right)\right]-\lambda_{m}^{s}\left[u^{\prime}\left(c_{m}^{s}\right)+u^{\prime}\left(c_{m f}^{s}\right)\right]=0 ; \\
& \quad\left[w_{f} u^{\prime}\left(c_{f}^{s}\right)-R^{\prime}\left(\tau_{f}^{s}\right)\right] \varphi^{\prime}\left[U_{f}^{s}\right] \\
& +\lambda_{f}^{s}\left[w_{f} u^{\prime}\left(c_{f}^{s}\right)-R^{\prime}\left(\tau_{f}^{s}\right)\right]-\lambda_{m}^{s}\left[w_{m} u^{\prime}\left(c_{m f}^{s}\right)-R^{\prime}\left(\tau_{f}^{s}\right)\right]=0 ; \\
& \quad\left[w_{m} u^{\prime}\left(c_{m}^{s}\right)-R^{\prime}\left(\tau_{m}^{s}\right)\right] \varphi^{\prime}\left[U_{m}^{s}\right] \\
& -\lambda_{f}^{s}\left[w_{f} u^{\prime}\left(c_{f m}^{s}\right)-R^{\prime}\left(\tau_{m}^{s}\right)\right]+\lambda_{m}^{s}\left[w_{m} u^{\prime}\left(c_{m}^{s}\right)-R^{\prime}\left(\tau_{m}^{s}\right)\right]=0,
\end{aligned}
$$

where $c_{f m}^{s}=\left(w_{f} \tau_{m}^{s}-P_{f}^{s}\right) / T_{f}$ and $c_{m f}^{s}=\left(w_{m} \tau_{f}^{s}+P_{f}^{s}\right) / T_{m}$. Using the definition (20), the three FOCs can be respectively rewritten as

$$
\begin{aligned}
& u^{\prime}\left(c_{f}^{s}\right)\left(\varphi^{\prime}\left[U_{f}^{s}\right]+\lambda_{f}^{s}\right)-u^{\prime}\left(c_{m}^{s}\right)\left(\varphi^{\prime}\left[U_{m}^{s}\right]+\lambda_{m}^{s}\right) \\
+ & \lambda_{f}^{s} u^{\prime}\left(c_{f m}^{s}\right)-\lambda_{m}^{s} u^{\prime}\left(c_{m f}^{s}\right)=0, \\
& u^{\prime}\left(c_{f}^{s}\right) M R S_{f}\left(\varphi^{\prime}\left[U_{f}^{s}\right]+\lambda_{f}^{s}\right) \\
- & \lambda_{m}^{s} u^{\prime}\left(c_{m f}^{s}\right) M R S_{m f}=0, \\
& u^{\prime}\left(c_{m}^{s}\right) M R S_{m}\left(\varphi^{\prime}\left[U_{m}^{s}\right]+\lambda_{m}^{s}\right) \\
- & \lambda_{f}^{s} u^{\prime}\left(c_{f m}^{s}\right) M R S_{f m}=0,
\end{aligned}
$$


where $M R S_{m f}^{s}=R^{\prime}\left(\tau_{f}^{s}\right) / u^{\prime}\left(c_{m f}^{s}\right)-w_{m}$ and $M R S_{f m}^{s}=R^{\prime}\left(\tau_{m}^{s}\right) / u^{\prime}\left(c_{f m}^{s}\right)-w_{f}$.

\section{A.6.1 Proof of point $(i)$}

Suppose that $\lambda_{m}^{s}>0$ and $\lambda_{f}^{s}=0$. From $(A .22), M R S_{m}^{s}=0$. Moreover, combining $(A .20)$ with $(A .21)$ yields:

$$
M R S_{f}^{s}=\left(1-\frac{u^{\prime}\left(c_{m}^{s}\right)\left(\varphi^{\prime}\left[U_{m}^{s}\right]+\lambda_{m}^{s}\right)}{u^{\prime}\left(c_{f}^{s}\right) \varphi^{\prime}\left[U_{f}^{s}\right]}\right) M R S_{m f}^{s}
$$

where $\left.\left(1-u^{\prime}\left(c_{m}^{s}\right)\left(\varphi^{\prime}\left[U_{m}^{s}\right]+\lambda_{m}^{s}\right) / u^{\prime}\left(c_{f}^{s}\right) \varphi^{\prime}\left[U_{f}^{s}\right]\right) \in\right] 0,1[$ by $(A .20)$ so that

$$
\frac{M R S_{f}^{s}}{M R S_{m f}^{s}}<1
$$

Recall that $M R S_{m f}^{s}=R^{\prime}\left(\tau_{f}^{s}\right) / u^{\prime}\left(c_{m f}^{s}\right)-w_{m}$ which using $M R S_{m}^{s}=0$ yields

$$
M R S_{m f}^{s}=\frac{R^{\prime}\left(\tau_{f}^{s}\right)}{u^{\prime}\left(c_{m f}^{s}\right)}-\frac{R^{\prime}\left(\tau_{m}^{s}\right)}{u^{\prime}\left(c_{m}^{s}\right)}
$$

Moreover, the binding self selection constraint (A.16) implies

$$
R\left(\tau_{f}^{s}\right)-R\left(\tau_{m}^{s}\right)=T_{m}\left[u\left(c_{m f}^{s}\right)-u\left(c_{m}^{s}\right)\right]
$$

so that two cases are possible:

(ia) either $c_{m f}^{s}<c_{m}^{s}$ so that by $(A .24), \tau_{f}^{s}<\tau_{m}^{s}$ which, using (A.23), yields $M R S_{m f}^{s}<0$ (and thus $M R S_{f}^{s}<0$ ).

(ib) or $c_{m f}^{s}>c_{m}^{s}$ so that by $(A .24), \tau_{f}^{s}>\tau_{m}^{s}$ which, using $(A .23)$, yields $M R S_{m f}^{s}>0$ (and thus $M R S_{f}^{s}>0$ ).

Note that, in case (ia), using (A.27), one has $c_{m}^{s}>c_{m f}^{s}>c_{f}^{s}$. Moreover, by (A.20), one has $u^{\prime}\left(c_{f}^{s}\right) \varphi^{\prime}\left[U_{f}^{s}\right]>u^{\prime}\left(c_{m}^{s}\right) \varphi^{\prime}\left[U_{m}^{s}\right]$ so that $U_{m}^{s}>U_{f}^{s}$.

\section{A.6.2 Proof of point $(i i)$}

Suppose that $\lambda_{f}^{s}>0$ and $\lambda_{m}^{s}=0$. From $(A .21), M R S_{f}^{s}=0$. Moreover, combining (A.20) with (A.22) yields:

$$
M R S_{m}^{s}=M R S_{f m}^{s}\left[1-\frac{u^{\prime}\left(c_{f}^{s}\right)\left(\varphi^{\prime}\left[U_{f}^{s}\right]+\lambda_{f}^{s}\right)}{u^{\prime}\left(c_{m}^{s}\right) \varphi^{\prime}\left[U_{m}^{s}\right]}\right],
$$


where $\left.1-u^{\prime}\left(c_{f}^{s}\right)\left(\varphi^{\prime}\left[U_{f}^{s}\right]+\lambda_{f}^{s}\right) / u^{\prime}\left(c_{m}^{s}\right) \varphi^{\prime}\left[U_{m}^{s}\right] \in\right] 0,1[$ by $(A .20)$ so that

$$
\frac{M R S_{m}^{s}}{M R S_{f m}^{s}}<1
$$

Remember that $M R S_{f m}^{s}=R^{\prime}\left(\tau_{m}^{s}\right) / u^{\prime}\left(c_{f m}^{s}\right)-w_{f}$ which using $M R S_{f}^{s}=0$ yields

$$
M R S_{f m}^{s}=\frac{R^{\prime}\left(\tau_{m}^{s}\right)}{u^{\prime}\left(c_{f m}^{s}\right)}-\frac{R^{\prime}\left(\tau_{f}^{s}\right)}{u^{\prime}\left(c_{f}^{s}\right)} .
$$

Moreover, the binding self selection constraint (A.15) implies

$$
R\left(\tau_{f}^{s}\right)-R\left(\tau_{m}^{s}\right)=T_{f}\left[u\left(c_{f}^{s}\right)-u\left(c_{f m}^{s}\right)\right]
$$

and by definition:

$$
\begin{aligned}
c_{m f}^{s} & =\frac{w_{m} \tau_{f}^{s}+P_{f}^{s}}{T_{m}}>\frac{w_{f} \tau_{f}^{s}+P_{f}^{s}}{T_{f}}=c_{f}^{s}, \\
c_{m}^{s} & =\frac{w_{m} \tau_{m}^{s}-P_{f}^{s}}{T_{m}}>\frac{w_{f} \tau_{m}^{s}-P_{f}^{s}}{T_{f}}=c_{f m}^{s},
\end{aligned}
$$

so that 2 cases are possible:

(iia) Either $c_{f}^{s}>c_{f m}^{s}$, so that by $(A .26), \tau_{f}^{s}>\tau_{m}^{s}$ which using $(A .25)$ yields $M R S_{f m}^{s}<0$ (and thus $M R S_{m}^{s}<0$ ).

(iib) or $c_{f}^{s}<c_{f m}^{s}$, so that by $(A .26), \tau_{f}^{s}<\tau_{m}^{s}$ which using (A.25) yields $M R S_{f m}^{s}>0$ (and thus $M R S_{m}^{s}>0$ ). Note that in case (iib), using (A.28), one has $c_{m}^{s}>c_{f m}^{s}>c_{f}^{s}$. Moreover, by $(A .20)$, one has $u^{\prime}\left(c_{f}^{s}\right) \varphi^{\prime}\left[U_{f}^{s}\right]<u^{\prime}\left(c_{m}^{s}\right) \varphi^{\prime}\left[U_{m}^{s}\right]$ so that $U_{f}^{s}>U_{m}^{s}$. 


\section{A.7 Gender neutral pensions with couples: the problem}

The optimal gender neutral allocation is obtained by solving:

$$
\begin{array}{ll}
\max _{P_{f}^{c}, P_{m}^{c}, \tau_{f}^{c}, \tau_{m}^{c}} & \varphi\left[T_{f} u\left(\frac{1}{\left(T_{m}+T_{f}\right)}\left(w_{m} \tau_{m}^{c}+w_{f} \tau_{f}^{c}+P_{m}^{c}+P_{f}^{c}\right)\right)-R\left(\tau_{f}^{c}\right)\right] \\
& +\varphi\left[T_{m} u\left(\frac{1}{\left(T_{m}+T_{f}\right)}\left(w_{m} \tau_{m}^{c}+w_{f} \tau_{f}^{c}+P_{m}^{c}+P_{f}^{c}\right)\right)-R\left(\tau_{m}^{c}\right)\right], \quad \text { (A.29) } \\
\text { s.t. } \quad & P_{m}^{c}+P_{f}^{c}=0, \\
& \left(T_{f}+T_{m}\right) u\left(\frac{1}{\left(T_{m}+T_{f}\right)}\left(w_{m} \tau_{m}^{c}+w_{f} \tau_{f}^{c}+P_{m}^{c}+P_{f}^{c}\right)\right)-R\left(\tau_{f}^{c}\right)-R\left(\tau_{m}^{c}\right) \geq \\
& \left(T_{f}+T_{m}\right) u\left(\frac{1}{\left(T_{m}+T_{f}\right)}\left(w_{m} \tau_{f}^{c}+w_{f} \tau_{m}^{c}+P_{m}^{c}+P_{f}^{c}\right)\right)-R\left(\tau_{f}^{c}\right)-R\left(\tau_{m}^{c}\right), \\
& \left(T_{f}+T_{m}\right) u\left(\frac{1}{\left(T_{m}+T_{f}\right)}\left(w_{m} \tau_{m}^{c}+w_{f} \tau_{f}^{c}+P_{m}^{c}+P_{f}^{c}\right)\right)-R\left(\tau_{f}^{c}\right)-R\left(\tau_{m}^{c}\right) \geq \\
& \left(T_{f}+T_{m}\right) u\left(\frac{1}{\left(T_{m}+T_{f}\right)}\left(w_{m}+w_{f}\right) \tau_{m}^{c}+2 P_{m}^{c}\right)-2 R\left(\tau_{m}^{c}\right), \quad\left(\lambda_{f}^{c}\right) \\
& \left(T_{f}+T_{m}\right) u\left(\frac{1}{\left(T_{m}+T_{f}\right)}\left(w_{m} \tau_{m}^{c}+w_{f} \tau_{f}^{c}+P_{m}^{c}+P_{f}^{c}\right)\right)-R\left(\tau_{f}^{c}\right)-R\left(\tau_{m}^{c}\right) \geq \\
& \left(T_{f}+T_{m}\right) u\left(\frac{1}{\left(T_{m}+T_{f}\right)}\left(w_{m}+w_{f}\right) \tau_{f}^{c}+2 P_{f}^{c}\right)-2 R\left(\tau_{f}^{c}\right) . \quad\left(\lambda_{m}^{c}\right)
\end{array}
$$

\section{A.8 Proof of Proposition 7}

Part (ii) of the proposition has already been established in the text and as mentioned there, this also establishes the "only if" case of part (i). We now complete the proof of part (i). As already mentioned, the fact that the "no switching" incentive constraint is satisfied when $\tau_{f}^{c F B} \leq \tau_{m}^{c F B}$ is obvious. We now must prove that none of the spouses want to deviate unilaterally from the equilibrium. Hence, it remains to be shown that incentive constraints (A.32) and (A.33) are also satisfied. This is done in Lemma 1, which completes the proof of Proposition 7 Intuitively, one can expect that this is the case because, even though $F B$ retirement ages are already distorted, such a deviation would bring the couple even further away from its $L F$ allocation. 
Lemma 1 A first-best allocation described in Proposition 4 satisfies constraints (A.32) and (A.33) if $\tau_{f}^{c F B} \leq \tau_{m}^{c F B}$ and $P_{f}^{c F B}=P_{m}^{c F B}=0$.

Proof. Because the right-hand sides and left-hand sides of (A.32) and (A.33) differ only in one dimension $\left(\tau_{m}\right.$ and $\left.\tau_{f}\right)$ it is sufficient to study the partial derivatives of $U$ defined by

$$
U=T u\left(\frac{w_{m} \tau_{m}+w_{f} \tau_{f}}{T}\right)-R\left(\tau_{m}\right)-R\left(\tau_{f}\right)
$$

where $T=T_{m}+T_{f}$. Differentiating (A.34), evaluated at the first best, and using equations (A.12), (A.11) and (18) to determine the sign we have

$$
\begin{aligned}
& \frac{\partial U}{\partial \tau_{f}}=w_{f} u^{\prime}\left(c^{F B}\right)-R^{\prime}\left(\tau_{f}^{F B}\right) \leq 0, \\
& \frac{\partial U}{\partial \tau_{m}}=w_{m} u^{\prime}\left(c^{F B}\right)-R^{\prime}\left(\tau_{m}^{F B}\right) \geq 0,
\end{aligned}
$$

with strict inequality when $\varphi$ is strictly concave. Note that when $U$ is strictly concave in $\left(\tau_{m}, \tau_{f}\right)$, as follows from our assumptions, the single variable functions of $\tau_{m}$ and $\tau_{f}$ obtained by fixing the other retirement age, are of course also strictly concave. Consequently, when $\tau_{f}^{c F B}<\tau_{m}^{c F B}$, the right-hand side of conditions (A.32) and (A.33) obtained by increasing $\tau_{f}$ or decreasing $\tau_{m}$, is always strictly smaller than the left hand side. Finally, when $\tau_{f}^{c F B}=\tau_{m}^{c F B}$ the two conditions are trivially satisfied as strict equalities.

\section{A.9 Results for the case where $v=10$}

The results obtained in this scenario are presented in Figure 5 for singles only and couples only and in Figure 6 for the case where singles and couples coexist. 


\begin{tabular}{|c|c|c|c|c|c|c|}
\hline & \multicolumn{3}{|c|}{ Singles only } & \multicolumn{3}{c|}{ Couples only } \\
\hline Allocations & $L F$ & $F B$ & $S B$ & $L F$ & $F B$ & $S B$ \\
\hline$c_{f}$ & 26277 & 26361 & 28491 & 29722 & 29629 & 28634 \\
\hline$c_{m}$ & 33135 & 33043 & 33069 & 29722 & 29629 & 28634 \\
\hline$\tau_{f}$ & 40.49 & 41.37 & 44.74 & 37.44 & 45.34 & 39.67 \\
\hline$\tau_{m}$ & 41.49 & 40.59 & 40.62 & 44.33 & 37.43 & 39.67 \\
\hline$P_{f}$ & 0 & 9292 & 9291 & 0 & 0 & 0 \\
\hline$P_{m}$ & 0 & -9292 & -9291 & 0 & 0 & 0 \\
\hline$P_{f}^{\prime}$ & 0 & 0 & 5836 & 0 & 7895 & 1034 \\
\hline$P_{m}^{\prime}$ & 0 & 0 & 0 & 0 & -7110 & -5965 \\
\hline$U_{f}$ & 951 & 952 & 951 & 1022 & 958 & 993 \\
\hline$U_{m}$ & 936 & 935 & 935 & 872 & 924 & 898 \\
\hline
\end{tabular}

Table 5: Scenario 3 with a very large degree of concavity of the $S W F$. The table shows the laissez-faire $(L F)$, the first best $(F B)$ and the gender-neutral second best $(S B)$ with singles only and couples only. Redistribution from single men to single women is still optimal. Gender neutrality remains thus detrimental to single women. Retirement ages in the couple are equalized. Gender neutrality is more detrimental to male spouses than in Scenario 2. 


\begin{tabular}{|c|c|c|c|}
\hline \multirow{4}{*}{ Singles } & Allocations & First Best & Second Best \\
\cline { 2 - 4 } & $c_{f}$ & 26287 & 26062 \\
\cline { 2 - 4 } & $c_{m}$ & 32947 & 33043 \\
\cline { 2 - 4 } & $\tau_{f}$ & 41.47 & 41.37 \\
\cline { 2 - 4 } & $\tau_{m}$ & 40.69 & 40.59 \\
\cline { 2 - 4 } & $P_{f}$ & 1074 & -8643 \\
\cline { 2 - 4 } & $P_{m}$ & -18998 & -9279 \\
\cline { 2 - 4 } & $P_{f}^{\prime}$ & 0 & -360 \\
\cline { 2 - 4 } & $P_{m}^{\prime}$ & 0 & 0 \\
\cline { 2 - 4 } & $U_{f}$ & 951 & 949 \\
\cline { 2 - 4 } & $U_{m}$ & 933 & 935 \\
\cline { 2 - 4 } & $c$ & 29665 & 29169 \\
\cline { 2 - 4 } & $\tau_{f}$ & 45.30 & 40.32 \\
\cline { 2 - 4 } & $\tau_{m}$ & 37.38 & 40.32 \\
\cline { 2 - 4 } & $P_{f}+P_{m}$ & 7682 & 7681 \\
\cline { 2 - 4 } & $P_{f}^{\prime}$ & 7904 & 2287 \\
\cline { 2 - 4 } & $P_{m}^{\prime}$ & -7116 & -4712 \\
\cline { 2 - 4 } & $U_{f}$ & 959 & 994 \\
\cline { 2 - 4 } & $U_{m}$ & 925 & 898 \\
\hline
\end{tabular}

Table 6: Scenario 3 with a very large degree of concavity of the $S W F$. The Table shows results when singles and couples coexist. Gender neutrality continues to impair both single women and male spouses, while it benefits single men and especially female spouses. The second best generates an overall redistribution from women to men. Singles men and single women are net contributors while couples are net recipients.. 